\author{
UNIVERSIDADE DE SÃO PAULO \\ FACULDADE DE MEDICINA DE RIBEIRÃO PRETO
}

ANA LUÍSA REZENDE MACHADO

Avaliação dos métodos de estimativa de idade de Cameriere e Willems em radiografias panorâmicas de indivíduos brasileiros

Ribeirão Preto

2019 


\section{Avaliação dos métodos de estimativa de idade de Cameriere e Willems em} radiografias panorâmicas de indivíduos brasileiros

\section{Versão Corrigida}

(A versão original encontra-se disponível tanto na Biblioteca da Unidade que aloja o Programa, quanto na Biblioteca Digital de Teses e Dissertações da USP)

Dissertação apresentada ao Departamento de Patologia e Medicina Legal da Faculdade de Medicina de Ribeirão Preto da Universidade de São Paulo para obtenção do título de Mestre em Ciência Médicas.

Área de Concentração: Patologia experimental

Orientador: Prof. Dr. Ricardo Henrique Alves da Silva

Ribeirão Preto 
Autorizo a reprodução e divulgação total ou parcial deste trabalho, por qualquer meio convencional ou eletrônico, para fins de estudo e pesquisa, desde que citada a fonte.

Machado, Ana Luísa Rezende

Avaliação dos métodos de estimativa de idade de Cameriere e Willems em radiografias panorâmicas de indivíduos brasileiros. Ribeirão Preto, 2019.

74 p. : il. ; $30 \mathrm{~cm}$

Dissertação de Mestrado, apresentada à Faculdade de Medicina de Ribeirão Preto/USP. Área de concentração: Patologia Experimental.

Orientador: Silva, Ricardo Henrique Alves.

1. Determinação da Idade pelos Dentes. 2. Identificação Humana. 3. Odontologia Legal. 4. Radiografia Panorâmica. 


\section{Folha de Aprovação}

Ana Luísa Rezende Machado

\section{Avaliação dos métodos de estimativa de idade de Cameriere e Willems em radiografias panorâmicas de indivíduos brasileiros}

Dissertação apresentada ao Departamento de Patologia e Medicina Legal da Faculdade de Medicina de Ribeirão Preto da Universidade de São Paulo para obtenção do título de Mestre em Ciência Médicas.

Área de Concentração: Patologia experimental

Aprovado em:

Banca Examinadora:

1) Prof.(a). Dr.(a).:

Instituição:

Julgamento: Assinatura:

2) Prof.(a). Dr.(a).:

Instituição:

Julgamento:

Assinatura:

3) Prof.(a). Dr.(a).:

Instituição:

Julgamento: Assinatura: 
ODedicatória 


\section{Dedico este trabalho,}

Aos meus pais, meus grandes exemplos de amor e dedicação, que sempre foram minha base e alicerce em todos os momentos e fundamentais para a conclusão de mais essa etapa em minha vida. 


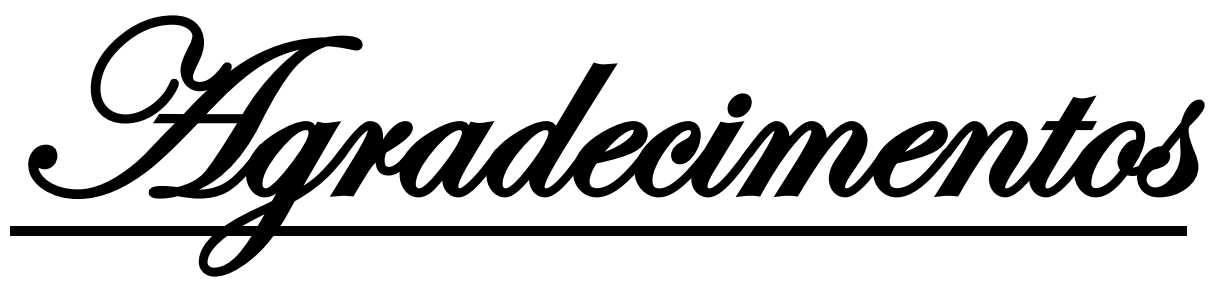




\section{Agradeço,}

À Universidade de São Paulo e à Faculdade de Medicina de Ribeirão Preto, especialmente a todos os funcionários da secretaria do Departamento de Patologia e Medicina Legal, por toda atenção e dedicação.

À Faculdade de Odontologia de Ribeirão Preto e ao Departamento de Estomatologia, Saúde Coletiva e Odontologia Legal pelo auxílio e estrutura oferecida durante toda a elaboração do presente trabalho.

Ao meu orientador, Prof. Dr. Ricardo Henrique Alves da Silva, por ser um exemplo de profissional com sua conduta ética, pelo seu amor pela profissão e também, por ser meu grande incentivo desde a graduação.

À Coordenação de Aperfeiçoamento de Pessoal de Nível Superior, pela concessão da bolsa de mestrado e pelo apoio financeiro para realização dessa pesquisa*.

Aos meus pais Cláudia e Marcelo, por estarem presentes durante todo esse percurso, por sempre me incentivarem a ser uma pessoa melhor, tanto em minha vida pessoal como profissional, e por serem meus maiores exemplos de dedicação.

Aos meus irmãos, Júlia e Gustavo, por serem meus primeiros e melhores amigos, por estarem sempre de ouvidos e braços abertos pra me acolher e nunca me deixarem desanimar.

Ao meu companheiro Felipe, por acreditar no meu potencial, por me fazer enxergar as situações sempre da melhor forma e por trazer alegria e leveza durante toda essa fase.

Aos meus colegas de mestrado, Bruna, Giovanna, Júlia, Larissa, Luciana, Paula, Paulo, Tamara, Silmara e Victor, por me acolherem desde o início e me darem todo o suporte durante o dia a dia. Especialmente à Bruna, Tamara e Silmara, as qui se tornaram minha segunda família.

*O presente trabalho foi realizado com apoio da Coordenação de Aperfeiçoamento de Pessoal de Nível Superior - Brasil (CAPES) - Código de Financiamento 001. 
"Um dia, quando olhares pra trás, verás que os dias mais belos foram aqueles em que lutaste."

Sigmund Freud 
Oresuma 


\section{RESUMO}

MACHADO, Ana Luísa Rezende. Avaliação dos métodos de estimativa de idade de Cameriere e Willems em radiografias panorâmicas de indivíduos brasileiros. 2019. 74 f. Dissertação (Mestrado em Patologia Experimental) - Faculdade de Medicina de Ribeirão Preto, Universidade de São Paulo, Ribeirão Preto, 2019.

A estimativa de idade possui grande destaque no âmbito forense por sua importância na formação do perfil biológico durante o exame pericial no morto, na avaliação da probabilidade de um indivíduo ter atingido uma idade juridicamente relevante e até mesmo na prática clínica, onde os profissionais da área da saúde estimam a idade para diagnosticar distúrbios do crescimento ou para um melhor planejamento do tratamento. Dessa forma, diversos estudos buscam desenvolver métodos cada vez mais precisos, baseados tanto no desenvolvimento quanto nas involuções esqueléticas e dentais. Visando os métodos odontológicos, o presente estudo objetivou estimar a idade dental utilizando os métodos de Cameriere e Willems, comparar os resultados entre os métodos e entre o sexo feminino e masculino, analisando a concordância entre as idades estimadas e as idades reais, assim como, verificar concordância entre a média das idades estimadas pelos dois métodos e as idades reais. Dois avaliadores realizaram a estimativa de idade por meio 180 radiografias panorâmicas de uma amostra com indivíduos brasileiros de 6 a 14 anos de idade, as quais apresentavam desde o incisivo central inferior esquerdo até 0 segundo molar inferior esquerdo. Foi possível observar que os métodos utilizados possuem grandes correlações com as idades reais da amostra feminina e masculina, mas o método de Willems apresentou uma superestimação, considerando as diferenças negativas entre as idades reais e as idades estimadas, sendo $-0,47$ para o sexo feminino e -0,39 para o sexo masculino, e o método de Cameriere demonstrou uma leve subestimação, sendo 0,05 para o sexo feminino e 0,03 para o sexo masculino. Além disso, foi averiguado que a média obtida entre as idades estimadas pelos dois métodos apresentou um discreto aumento da concordância com a idade real.

Palavras-chave: Determinação da Idade pelos Dentes, Identificação Humana, Odontologia Legal, Radiografia Panorâmica. 


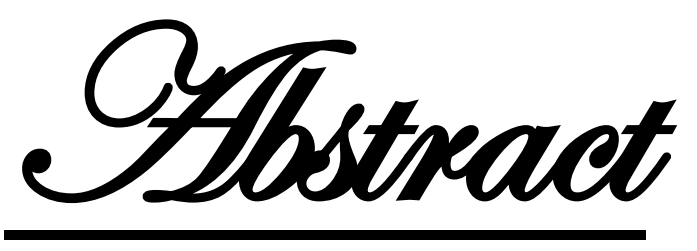




\begin{abstract}
MACHADO, Ana Luísa Rezende. Evaluation of Cameriere and Willems age estimation methods in ortopantomograph of Brazilian individuals. 2019. $74 \mathrm{f}$. Dissertação (Mestrado em Patologia Experimental) - Faculdade de Medicina de Ribeirão Preto, Universidade de São Paulo, Ribeirão Preto, 2019.
\end{abstract}

The estimation of age has a highlight on forensic area because its importance in formation of the biological profile during the examination in the dead body, in evaluation of the probability of a person has reached a legally relevant age and in clinical practice, where professionals estimate the age for diagnose growth disorders or for a better treatment plan. Thus, several studies aim to develop increasingly accurate methods based on skeletal and dental development or on involutions. Based on dental methods, the present study aimed to estimate the dental age using the Cameriere and Willems methods, to compare the results between the methods and between females and males, analyzing the agreement between estimated ages and real ages, as well as the agreement between means of ages estimated by each method and the real ages. Two evaluators estimated the ages using 180 panoramic radiographs of a sample with Brazilian individuals from 6 to 14 years old, which presented from the left lower central incisor to the left lower second molar. It was possible to observe that the methods used have great correlations with the real ages of the female and male sample, but the Willems method indicated an overestimation, considering the negative differences between the real ages and the estimated ages, being -0.47 for the sex female and 0.39 for males, and Cameriere method showed a slight underestimation, being 0.05 for females and 0.03 for males. In addition, it was found that the mean between ages estimated by the both methods provided a slight increase in agreement with real age.

Key-words: Age Determination by Teeth, Forensic Dentistry, Human Identification, Panoramic Radiography. 
Qlista de Hustrasões 


\section{LISTA DE ILUSTRAÇÕES}

Figura 1 - Exemplo de mensuração da abertura do ápice e do comprimento dos sete dentes inferiores esquerdos por meio do software ImageJ 35

Figura 2 - Estágios de desenvolvimento dental segundo Demirjian, Goldstein e Tanner (1973) 35

Figura 3 - Tabelas de score para o sexo masculino e feminino, segundo Willems et al. (2001) 36

Figura 4 - Gráficos tipo Box Plot da análise Teste Reteste das idades estimadas por cada avaliador para o sexo feminino 39

Figura 5 - Gráficos tipo Box Plot da análise Teste Reteste das idades estimadas por cada um dos avaliadores para o sexo masculino 40

Figura 6 - Coeficiente de Correlação Intraclasse (ICC) das idades estimadas por ambos os métodos e avaliadores no Teste Reteste, para o sexo feminino

Figura 7 - Coeficiente de Correlação Intraclasse (ICC) das idades estimadas por ambos os métodos e avaliadores no Teste Reteste, para o sexo masculino

Figura 8 - Gráficos tipo Box Plot das idades reais e estimadas por ambos os métodos, assim como suas médias, para o sexo feminino

Figura 9 - Gráficos tipo Box Plot das idades reais e estimadas por ambos os métodos, assim como suas médias, para o sexo masculino 43

Figura 10 - Coeficiente de Correlação Intraclasse (ICC) entre as idades reais e as idades estimadas por ambos os métodos, assim como suas médias, para o sexo feminino 45

Figura 11 - Coeficiente de Correlação Intraclasse (ICC) entre as idades reais e as idades estimadas por ambos os métodos, assim como suas médias, para o sexo masculino 46

Figura 12 - Diferença entre as idades reais e as idades estimadas por ambos os métodos, assim como suas médias, para o sexo feminino 48

Figura 13 - Diferença entre as idades reais e as idades estimadas por ambos os métodos, assim como suas médias, para o sexo masculino 


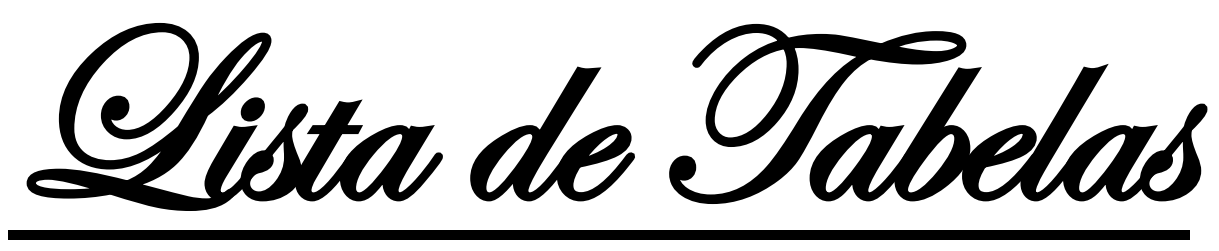




\section{LISTA DE TABELAS}

Tabela 1 - Coeficientes de Correlação Intraclasse (ICC) dos dados de Teste Reteste para cada avaliador por ambos os métodos e sexos

Tabela 2 - Coeficientes de Correlação Intraclasse (ICC) entre as idades reais e idades estimadas do sexo feminino e masculino por ambos os avaliadores e métodos, assim como a média entre eles 44

Tabela 3 - Comparação entre idade real e estimada de cada método para cada avaliador 50

Tabela 4 - Comparação entre idade real e estimada de cada método 51 
Qfista de OAbreviaturas e Origlas 


\section{LISTA DE ABREVIATURAS E SIGLAS}

CAAE Certificado de Apresentação para Apreciação Ética

DNA Ácido Desoxirribonucleico

DVI Identificação de Vítima de Desastres

ICC Coeficiente de Correlação Intraclasse

INTERPOL Organização Internacional de Polícia Criminal

USP Universidade de São Paulo 


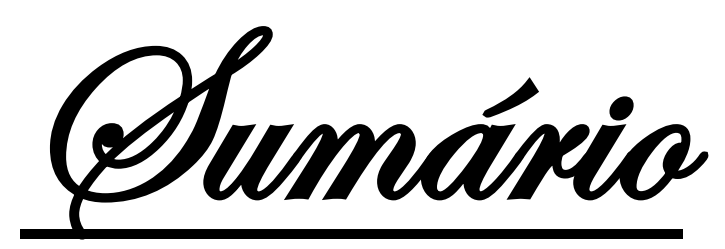




\section{SUMÁRIO}

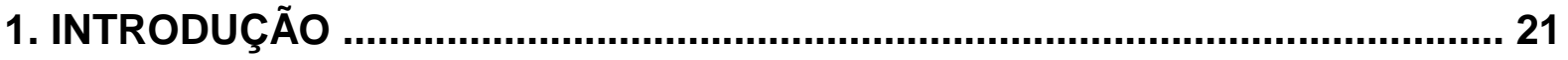

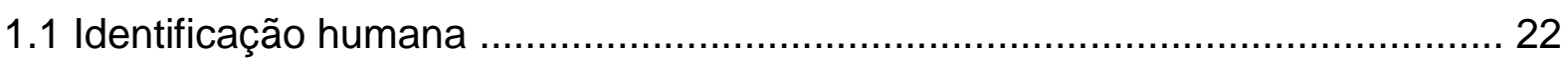

1.2 A importância da estimativa de idade ........................................................... 24

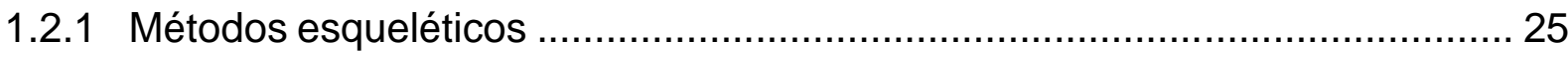

1.2.2 Métodos odontológicos ……................................................................. 26

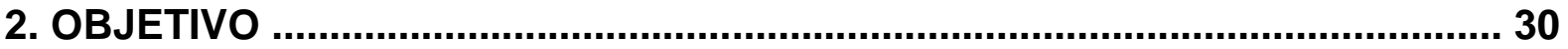

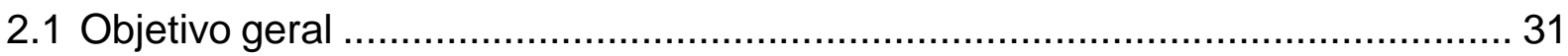

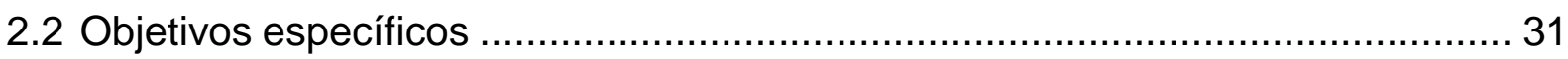

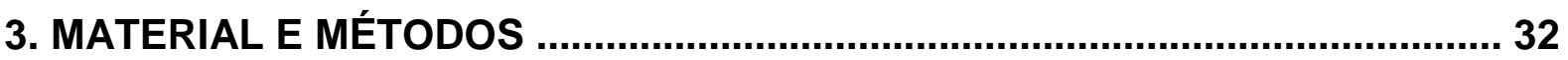

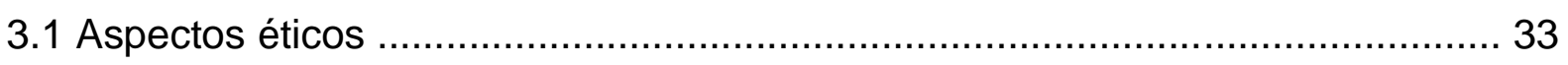

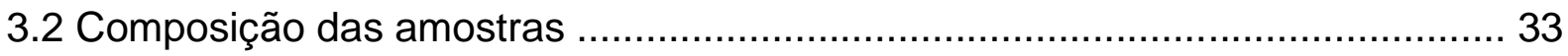

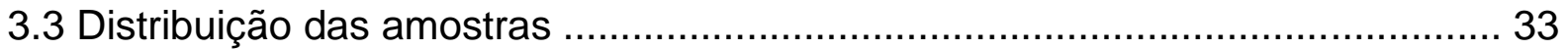

3.4 Estimativa de idade pelo método de Cameriere e Willems ……...................... 34

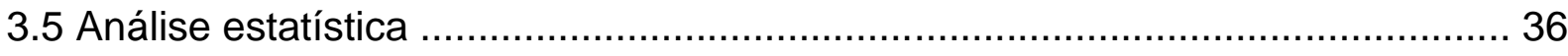

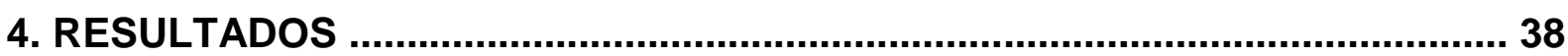

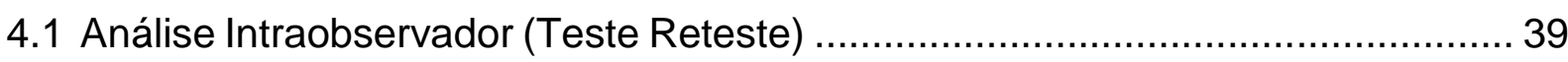

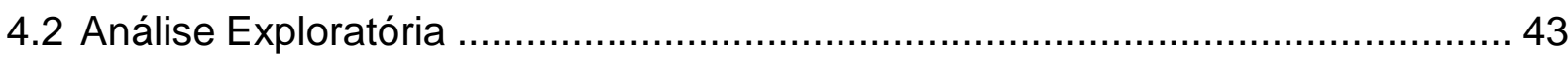

4.3 Concordância entre as idades reais e estimadas pelo ICC ............................... 44

4.4 Concordância entre as idades reais e estimadas pelo método de Bland-

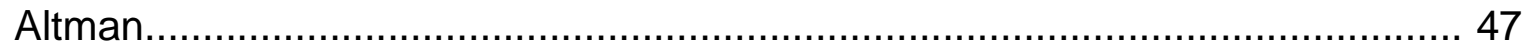

4.5 Comparação entre as idades reais e estimadas ............................................ 50

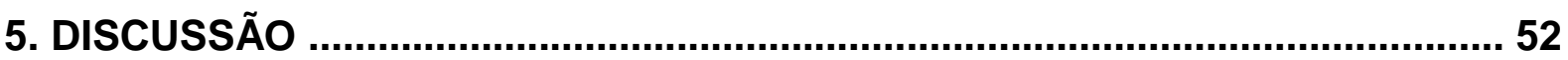

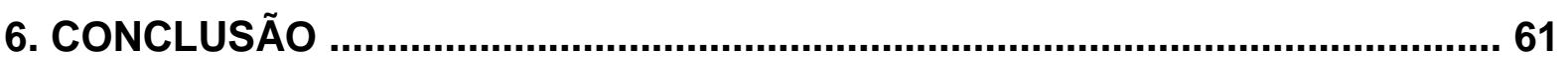

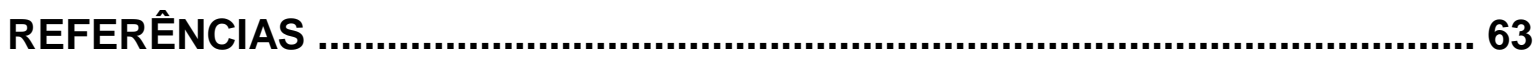

ANEXO A

APÊNDICE A

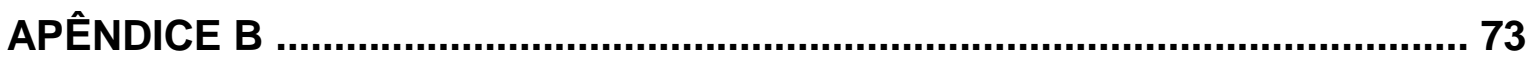




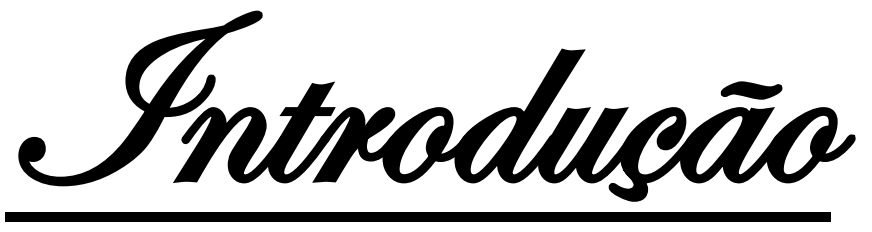




\section{INTRODUÇÃo}

\subsection{Identificação humana}

A identidade pode ser definida como o conjunto de características que diferenciam uma pessoa das demais e igual apenas a si mesma, tanto no âmbito físico como jurídico. Já a identificação é o processo técnico, científico e objetivo que estabelece a identidade de uma pessoa ou coisa (FREITAS, 2013; MOREIRA, 2013).

Tendo em vista que qualquer cidadão possui o direito de ser identificado para que todos os seus direitos sejam resguardados, assim como, ser cobrado pelos seus deveres, o processo de identificação torna-se indispensável à sociedade, respeitando os princípios éticos e morais que estão envolvidos (ARAÚJO, 2013; CARVALHO et al., 2009).

Dessa forma, a identificação humana está inserida em diversos contextos, tanto em situações do dia a dia como adquirir bens, abrir uma conta bancária ou obter documentos pessoais, quanto em situações adversas, como ocorre nos desastres em massa (ARAÚJO; PASQUALI, 2006; CARVALHO et al., 2009). Além desses casos, há ainda as questões religiosas, sociais e emocionais envolvidas, visto que 0 sepultamento dos indivíduos identificados proporciona um maior conforto aos membros familiares (MODESTO; JUNIOR, 2017).

Para que a técnica de identificação utilizada seja válida, é importante que atenda aos seguintes princípios técnicos e biológicos: unicidade (pertencente apenas a um indivíduo), imutabilidade (características que não se alteram com o decorrer do tempo), praticabilidade (deve ser de fácil aplicação), classificabilidade (classificar e arquivar os registros obtidos) e perenidade (persiste à ação do tempo) (TORNAVOI; SILVA, 2010).

À vista disso, a Organização Internacional de Polícia Criminal (INTERPOL) elaborou um Guia de Identificação de Vítima de Desastres (DVI) que considera a datiloscopia, a Odontologia e a análise do ácido desoxirribonucleico (DNA) como métodos primários de identificação por atenderem os requisitos técnicos e biológicos supracitados e por possuírem alto grau de confiabilidade e precisão (ARAÚJO, 2013; INTERPOL, 2018; MELANI, 1998). Já a Antropologia Forense, as vestimentas e eventuais tatuagens encontradas, podem ser consideradas como métodos secundários por auxiliarem o processo de identificação (ANDRADE, 2017). 
Entretanto, os métodos primários são possíveis de serem utilizados apenas quando há um suspeito para realizar a comparação com os registros anteriores à morte. Quando não há suspeitos para gerar a comparação, deve-se empregar os métodos reconstrutivos, os quais geram probabilidades e visam levantar o maior número de informações pertencentes à pessoa que se deseja identificar, como sexo, ancestralidade, estatura, idade, destreza manual, anomalias e patologias, apresentando um perfil biológico para direcionar a busca e diminuir a gama de possibilidades para futuras comparações (MELANI, 1998; SOARES, 2008).

A estimativa do sexo mostra resultados bastante confiáveis, especialmente quando se trata de indivíduos adultos, nos quais o dimorfismo sexual se dá pelo desenvolvimento ósseo já consolidado (COSTA, 2002). As distinções entre o sexo masculino e feminino podem ser encontradas em diversas estruturas ósseas, como a pelve, crânio e mandíbula principalmente, sendo que a pelve é responsável por fornecer os elementos mais fidedignos (VELHO; GEISER; ESPINDULA, 2017). Os acidentes anatômicos nos crânios e nas mandíbulas masculinas são mais pronunciados quando comparados às estruturas femininas, as quais são menos salientes e marcantes, resultando em traços mais delicados (BUCHAIM; ISSA, 2018).

Já a estimativa de ancestralidade se apresenta como um grande obstáculo na população brasileira, dado a grande miscigenação existente com muitas características populacionais presentes em um mesmo indivíduo, como particularidades de origem caucasiana, negroide ou asiática (OTTO, 2016). É fundamental a diferenciação entre o termo ancestralidade e etnia, visto que esta última abrange elementos culturais, não passíveis de análise antropológica (VELHO; GEISER; ESPINDULA, 2017).

Em relação à estimativa da estatura, diversos estudos trazem uma proporção entre os ossos longos e a estatura do corpo de acordo com o sexo (COSTA, 2002). Segundo Freire (2000), os ossos mais importantes para este tipo de estimativa são, respectivamente, o fêmur e a tíbia, quando comparados a outros ossos, como úmero e rádio.

A estimativa de idade é baseada no desenvolvimento ósseo ou dental, na estabilização e no envelhecimento, os quais são estudados cuidadosamente para elaboração de métodos científicos cada vez mais precisos, visto a dificuldade dada pelas variações individuais e influências ambientais (BUCHAIM; ISSA, 2018; COSTA, 2002). 


\subsection{A importância da estimativa de idade}

Dentre os métodos utilizados para levantar características individuais de uma pessoa, a estimativa de idade é um dos mais utilizados, visto que além de auxiliar na formação do perfil biológico durante o exame pericial no morto, íntegro ou em fragmentos, pode avaliar a probabilidade do indivíduo ter atingido uma idade juridicamente relevante durante o exame em pessoas vivas (CFO, 2005; MORENO; PONTES; RABELLO, 2014).

Nesse sentido, a estimativa de idade torna-se fundamental na esfera civil, a qual é comumente utilizada em casos de adoção (GIBELLI; DE ANGELIS; CATTANEO, 2015), pedidos de asilo de refugiados (KARKHANIS; MACK; FRANKLIN, 2014) e ausência ou falsidade de registro civil (ALQAHTANI et al., 2017), visto que a legislação brasileira estabelece os direitos e deveres civis de acordo com os períodos etários, como direito a aposentadoria ou pensão alimentícia. Já no âmbito criminal, está frequentemente presente em casos de criminosos que alegam ser menores de dezoito anos e em casos de crimes contra crianças e adolescentes, como estupro, aborto, homicídio, tráfico e roubo, por exemplo (SCHMIDT, 2004).

Dessa forma, se faz necessária a verificação da caracterização dos períodos etários para diferenciar as penas em casos criminais, sendo possível classificar o indivíduo como incapaz (menores de dezoito anos) ou capaz (maiores de dezoito anos), dado que os menores de dezoito anos são considerados penalmente inimputáveis e assim, alvo de medidas tutelares educativas (BRASIL, 1940).

Semelhantemente, é de suma importância a classificação de um indivíduo como idoso, onde se enquadram pessoas com sessenta anos ou mais, segundo o Estatuto do Idoso, assegurando direitos pertencentes a esse período etário na esfera civil e criminal (BRASIL, 2003).

O processo de estimativa de idade em pessoas vivas está em ascensão atualmente, visto os diversos problemas enfrentados por cidadãos em diferentes países, como políticas autoritárias, guerras civis e extrema pobreza. À vista disso, os países que recebem e protegem esses indivíduos, tradicionalmente países europeus e da América do Norte, possuem a importante função de lhes fornecer documentações para trabalhar, ter acesso à saúde e educação, sendo de suma importância a estimativa de idade para garantir seus direitos e deveres (DOMINGUEZ; 
BAENINGER, 2006; SANTINHO, 2009). Já na América do Sul, o Brasil é o país que abriga o maior número de refugiados, mesmo com a diversas dificuldades de integração, em razão dos diferentes costumes culturais e dificuldades com o idioma (SANTANA, 2018).

Neste contexto, é fundamental a diferenciação entre idade biológica e idade cronológica, visto que nos casos supracitados não há conhecimento da idade cronológica, a qual é definida como o tempo decorrido desde o nascimento. Assim, a estimativa da idade biológica se torna necessária, ou seja, os métodos científicos são empregados na complexa tarefa de estimar o período decorrido a partir da análise do desenvolvimento de tecidos ou órgãos (ANASTÁCIO, 2016).

Paralelamente, muitos profissionais da saúde, visando o melhor planejamento do tratamento, estimam a idade biológica do seu paciente mesmo sabendo a idade cronológica, seja para diagnosticar distúrbios de crescimento e deficiências hormonais ou até mesmo, para determinar quando ocorrerá um crescimento facial suficiente para o futuro tratamento ortodôntico, por exemplo (CARVALHO et al., 2010; NETO; ALMEIDA; LEITE, 2000).

\subsubsection{Métodos esqueléticos}

Para que um método de estimativa de idade seja considerado válido e ideal, deve ter sido apresentado à comunidade científica por meio de publicação com base estatística e taxas de erros descritas claramente, possuir a maior precisão possível dos resultados e respeitar os princípios éticos e legais vigentes, principalmente em casos de indivíduos vivos (RITZ-TIMME et al., 2000).

Dessa forma, diversos métodos foram desenvolvidos para este fim, tanto esqueléticos como dentais. Os métodos esqueléticos são feitos pela avaliação do crescimento dos centros de ossificação até a finalização com a fusão das epífises e das diáfises, como por exemplo, a ossificação do osso carpo e metacarpo e da união epifisária das falanges por meio de radiografias do punho e mão esquerdos (CARVALHO et al., 2010; SANTORO et al., 2009). Outros ossos também são muito utilizados para estimar a idade de um indivíduo, como ocorre com os diferentes períodos de fusão das suturas cranianas (COSTA, 2002; SHEDGE; KANCHAN, 2019) e a completa soldadura da epífise proximal do úmero (EKIZOGLU et al., 2019). 
Para a estimativa de idade no adulto e no idoso são utilizadas as análises de involução senil, realizadas por meio de alterações degenerativas na coluna vertebral, como os osteófitos, e nas articulações dos membros superiores e inferiores, como as artroses. As transformações histológicas também podem fornecer informações complementares, como a variação dos diâmetros médios dos canais de Havers do tecido ósseo (FEREMBACH; SCHWIDETZKY; STLOUKAL, 1979).

Contudo, o desenvolvimento ósseo é mais susceptível à influência de inúmeros fatores, como patologias, deficiências hormonais e nutricionais, quando comparado à mineralização dental, ou seja, os métodos esqueléticos podem ser fortemente influenciados pelo grupo socioeconômico que o indivíduo está inserido (GONÇALVES; ANTUNES, 1999; SCHMELING et al., 2007). Dessarte, os métodos pelo exame dos elementos dentais possuem uma maior aproximação da idade cronológica, além de serem mais resistentes à putrefação, à ação da temperatura e de produtos químicos (GONÇALVES; ANTUNES, 1999; MANJUNATHA; SONI, 2014; SWAMI et al., 1992).

\subsubsection{Métodos odontológicos}

Na Odontologia, o primeiro marco histórico ocorreu ainda na Roma Antiga, onde os indivíduos do sexo masculino eram julgados como aptos a servir o exército assim que os segundos molares estivessem totalmente erupcionados ( $\mathrm{SHAH}$ et al., 2019). Já o primeiro estudo sobre estimativa de idade por meio da análise dental, foi realizado por Saunders (1837), o qual foi utilizado para investigar o trabalho infantil que não era autorizado para crianças menores de nove anos no Reino Unido.

Sabendo que os dentes são estruturas protegidas por lábios, língua e bochechas e mostram relativamente boa preservação mesmo após anos de inumação, por serem as estruturas mais resistentes do corpo humano aos processos de degradação, os mesmos se tornam muitas vezes o método de escolha em identificações humanas nos desastres naturais, guerras e acidentes de grande magnitude, onde os corpos se encontram, frequentemente, em avançado estado de decomposição (GOUVEIA, 2016; ZILIO; BASUALDO; CRUZ, 2012).

O desenvolvimento dental é um processo complexo que envolve etapas celulares e moleculares. O início da erupção do primeiro elemento da dentição decídua, também chamada de temporária, ocorre entre o quarto e o décimo mês de vida e finaliza a erupção de seus vintes dentes decíduos até trinta meses após o 
nascimento (DUARTE et al., 2011; MAFRA et al., 2012; PATRIANOVA; KROLL; BÉRZIN, 2004). Posteriormente, o primeiro elemento dental da dentição permanente começa sua erupção por volta de seis anos, assim, o período existente entre os seis até os onze anos, é denominado de dentição mista, devido a presença de elementos dentais das duas dentições supracitadas (MOYERS, 1991; SULZLER et al., 2018).

Dessa forma, os métodos de estimativa de idade dental podem ser realizados tanto diretamente por meio do exame clínico do indivíduo, observando apenas o irrompimento dental, quanto indiretamente, por meio de exames de imagem complementares, nos quais podem ser avaliados a cronologia de erupção e também o grau de desenvolvimento e mineralização dos elementos dentais (FURTUNATO; SOUTO; PIANA, 2018).

Todos os métodos desenvolvidos possuem suas indicações corretas, as quais devem ser observadas em cada caso específico (FURTUNATO; SOUTO; PIANA, 2018). Por exemplo, para casos de crianças ou adolescentes, deve-se utilizar métodos que envolvam a dentição decídua ou mista, as quais levam em consideração a mineralização e/ou erupção dental. Mas se o indivíduo for considerado adulto, são preconizados métodos baseados na involução dental com suas características de envelhecimento, como o desgaste dental, o escurecimento e o volume da câmara pulpar (CORREIA; BEZERRA, 2011).

Para a aplicação de métodos que geralmente são utilizados em crianças e adolescentes, seja na dentição decídua ou mista, é importante diferenciar os termos formação dental e cronologia de erupção. O primeiro é fundamentado na mineralização dos dentes, a qual só é possível por meio de exames de imagem. $\mathrm{O}$ segundo conceito abrange a sequência de aparecimento dos diferentes elementos dentais na cavidade oral, ou seja, é possível que se faça diretamente no exame clínico (MANJUNATHA; SONI, 2014).

Baseado na sequência de erupção dental, AIQahtani, Hector e Liversidge (2010) desenvolveram um atlas que pode ser utilizado na comparação direta com a radiografia panorâmica do indivíduo. É fundamental destacar que neste método não há diferença entre o sexo masculino e feminino, além disso, os autores consideram que a erupção dental se inicia quando o dente emerge do osso alveolar.

Entretanto, a cronologia de erupção pode ser afetada por fatores exógenos, como o espaço do arco dental, extração ou perda precoce de dentes decíduos e dentes impactados ou inclinados, podendo assim, atrasar ou adiantar o processo de 
erupção dependendo do grau de desenvolvimento do elemento permanente no momento da influência externa (JAVADINEJAD; SEKHAVATI; GHAFARI, 2015). Já a formação dental é mais segura para estimar a idade do indivíduo, dado que é controlada, majoritariamente, por fatores genéticos e populacionais (MANJUNATHA; SONI, 2014).

À vista disso, diversos métodos baseados na formação dental foram desenvolvidos para estimar a idade de crianças e adolescentes por meio de imagens radiográficas. Massler e Schour (1941) estudaram as linhas incrementais que se depositam uma sobre a outra até a completa formação da coroa e início da formação radicular e desenvolveram, assim, um atlas que permite verificar e comparar tanto 0 nível de erupção quanto o grau de desenvolvimento dental.

Na sequência, inúmeros estudos foram realizados, como em 1960, quando Nolla estabeleceu dez estágios de mineralização de todos os dentes permanentes superiores e inferiores, atribuindo um valor para cada um desses estágios. A soma de tais valores são comparados a uma tabela de maturação desenvolvida para alcançar uma estimativa de idade (NOLLA, 1960).

Semelhantemente, Demirjian, Goldstein e Tanner (1973) estabeleceram oito estágios de desenvolvimento $(\mathrm{A}-\mathrm{H})$ a partir dos sete dentes inferiores esquerdos. Assim, após a classificação e soma dos valores de todos os dentes, é obtido o "Maturity Score", o qual é convertido em idade de acordo com uma tabela para cada sexo.

Baseado na metodologia de Demirjian, Willems et al. (2001) utilizaram a mesma classificação dos sete dentes inferiores esquerdos, entretanto, sintetizou o processo de estimativa de idade. Os autores retiraram a tabela do "Maturity Score" e criaram apenas uma para cada sexo, onde as classificações estipuladas anteriormente são somadas, obtendo a idade estimada.

Diferente dos métodos já citados, nos quais se faz necessária uma comparação direta das radiografias panorâmicas com cada estágio de formação dental estabelecido, ou seja, métodos não métricos e comparativos, Cameriere, Ferrante e Cingolani (2006) propuseram um método realizado por meio de mensurações. Os autores se basearam em uma fórmula que abrange o sexo e as mensurações da altura de cada dente inferior esquerdo e da abertura de seus respectivos ápices, estabelecendo assim, uma análise métrica para estimar a idade. 
Seguindo para métodos de estimativa de idade na fase final da adolescência e para jovens adultos, onde a estimativa de maioridade se faz muitas vezes necessárias por questões sociais, civis ou criminais, Cameriere et al. (2008) utilizaram o índice de maturidade do terceiro molar inferior. Este índice é definido como a razão da soma da abertura dos ápices radiculares sobre o comprimento total do dente. Nos dois métodos desenvolvidos pelos autores, tanto para estimativa de idade quanto de maioridade, é fundamental destacar que caso haja desenvolvimento radicular completo, o dividendo é igual a zero.

Para a estimativa de idade em adultos, a análise do desenvolvimento dental se torna inviável, dado que indivíduos com mais de trinta anos já concluíram seu processo de mineralização. Neste contexto, os métodos desenvolvidos são baseados nos fenômenos involutivos dos elementos dentais (CORREIA; BEZERRA, 2011).

Isto posto, Gustafson (1950) desenvolveu o primeiro método para a utilização em adultos. Para isso, o autor desenvolveu uma fórmula de regressão linear que envolve diversas características degenerativas, como atrição, formação de dentina secundária, localização do ligamento periodontal, deposição de cemento, reabsorção radicular e translucidez da dentina radicular. Entretanto, este método só pode ser aplicado em casos post mortem, visto a necessidade de extração dental.

Já o método de Kvaal et al. (1995), permite que seja utilizado nos exames em pessoas vivas por utilizar mensurações radiográficas. A análise elaborada pelos autores consiste na razão de medidas da câmara pulpar e do conduto radicular de dentes uniradiculares para relacionar com a aposição de dentina secundária.

Portanto, é possível observar que existem diversos métodos de estimativa de idade com diferentes análises e finalidades. Para estabelecer qual metodologia é a mais apropriada para determinado caso, é preciso levar em consideração a precisão oferecida pelo método, os custos envolvidos, a qualificação do examinador, o tempo e os equipamentos necessários (SCHMELING et al., 2007).

Além disso, para verificar a aplicabilidade do método de escolha, o mesmo deve ser estudado na população em questão, dado as inúmeras características populacionais, como diferenças culturais, climáticas, nutricionais e socioeconômicas, principalmente em um país miscigenado e com grandes dimensões territoriais como o Brasil (KURITA, 2004). 
Oyjetivo 


\section{OBJETIVO}

\subsection{Objetivo geral}

Estimar a idade dental, por meio de radiografias panorâmicas, em uma amostra de indivíduos brasileiros com idade entre 6 e 14 anos, utilizando os métodos de Cameriere (métrico) e de Willems (não métrico).

\subsection{Objetivos específicos}

Comparar as concordâncias de cada método com as idades reais e analisar se há diferenças entre o sexo feminino e masculino. Assim como, verificar se a média entre as idades estimadas pelos dois métodos é capaz de aumentar a concordância com a idade real. 


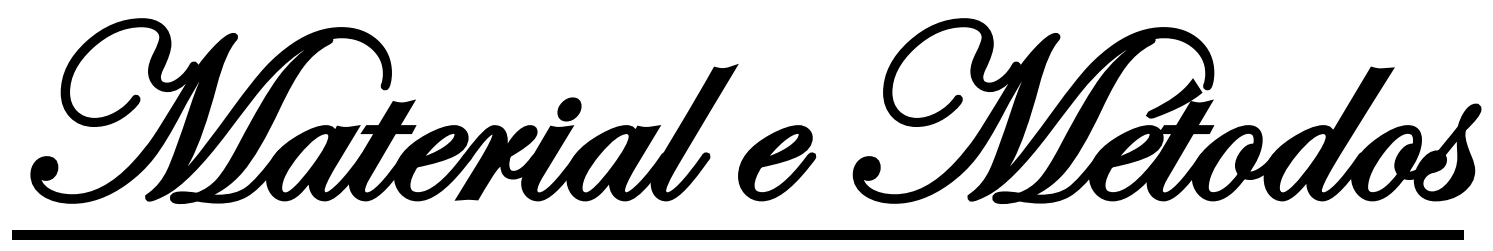




\section{MATERIAL E MÉTODOS}

\subsection{Aspectos éticos}

O projeto de pesquisa foi submetido e aprovado pelo Comitê de Ética em Pesquisa da Faculdade de Odontologia de Ribeirão Preto da Universidade de São Paulo sob o número CAAE 06634919.7.0000.5419 (ANEXO A), a fim de cumprir todas as exigências da Resolução 466/2012.

\subsection{Composição das amostras}

Para compor as amostras utilizadas no estudo, foram selecionadas 180 radiografias panorâmicas do acervo da Faculdade de Odontologia de Ribeirão Preto da Universidade de São Paulo, sendo 90 radiografias do sexo feminino e 90 do sexo masculino de indivíduos de 6 a 14 anos.

Os critérios de inclusão das radiografias panorâmicas foram: a boa resolução da imagem e a presença do incisivo central inferior esquerdo até o segundo molar inferior esquerdo (sete dentes inferiores esquerdos). As radiografias que apresentaram baixa resolução, alterações dentais de desenvolvimento, ausência ou fraturas de elementos dentais no hemiarco inferior esquerdo, não entraram na composição da amostra.

\subsection{Distribuição das amostras}

Dessa forma, o total de 180 radiografias foi dividido em duas amostras: Amostra 1 - composta por 90 radiografias panorâmicas de indivíduos de 6 a 14 anos do sexo feminino, sendo 10 radiografias por idade; e Amostra 2 - composta por 90 radiografias panorâmicas de indivíduos de 6 a 14 anos do sexo masculino, sendo 10 radiografias por idade.

Após a distribuição das radiografias nas duas amostras, as mesmas receberam códigos distribuídos de forma aleatória e foram tabuladas em uma planilha do Microsoft Exce ${ }^{\circledR}$ (Microsoft; Washington, USA) com os seguintes dados: código, sexo, data de nascimento, data da tomada radiográfica e idade em anos. Dessa forma, no momento da aplicação do métodos, os avaliadores tiveram acesso apenas às radiografias panorâmicas e seus códigos correspondentes. 


\subsection{Estimativa de idade pelos métodos de Cameriere e de Willems}

Ambas as amostras foram analisadas por dois avaliadores previamente calibrados, que realizaram a estimativa de idade por meio do método de Cameriere (métrico) e do método de Willems (não métrico). Em um primeiro momento, a calibração foi realizada com os avaliadores reunidos para a padronização das medições e classificações necessárias para a utilização dos métodos. Posteriormente, foram realizadas as estimativas de idade em 30 radiografias aleatórias com os avaliadores separados para a consecutiva comparação e discussão dos resultados.

O método de Cameriere, Ferrante e Cingolani (2006), classificado no presente estudo como método 1, foi baseado nas mensurações das aberturas dos ápices dos sete dentes inferiores do lado esquerdo. Para os dentes com uma raiz, é medida a distância entre os lados internos do ápice aberto, já para os dentes com duas raízes, a soma das distâncias dos lados internos dos dois ápices abertos. Além disso, para diminuir as possíveis diferenças entre angulações e distorções das diversas radiografias, as medições citadas são normalizadas por meio da divisão pelo comprimento total do elemento dental, o qual é medido da altura máxima do centro do dente até o final do desenvolvimento radicular. Dessa forma, é utilizada a seguinte fórmula:

$$
(8,971)+\left(0,375^{\star} G\right)+\left(1.631^{\star} X 5\right)+\left(0,674^{\star} N\right)-\left(1,034^{\star} S\right)-\left(0,176^{\star} S\right)^{\star} N
$$

Na qual: $G$ - gênero do indivíduo (1 para homens e zero para mulheres); $X$ - abertura do ápice sobre a medida da altura do dente;

$S$ - soma dos valores de $X$ para cada dente inferior do lado esquerdo; $N$ - número de ápices fechados.

É fundamental observar que caso haja desenvolvimento radicular completo, o valor da abertura do ápice é substituído por zero e o valor do comprimento do dente, substituído por 1.

Para realizar as mensurações necessárias, foi utilizado o software ImageJ (Wayne Rasband; National Institutes of Health, USA), assim, as medidas dos ápices e dos comprimentos (Figura 1) dos sete dentes inferiores esquerdos foram efetuadas. 
Figura 1 - Exemplo de mensuração da abertura do ápice e do comprimento dos sete dentes inferiores esquerdos por meio do software ImageJ.

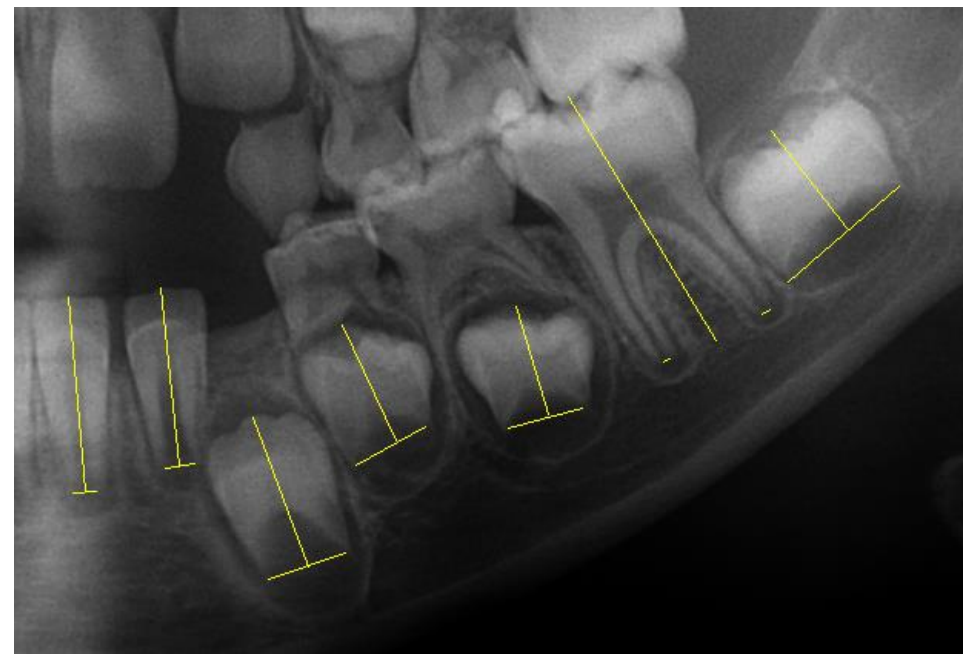

Fonte: Imagem de autoria própria.

O método de Willems et al. (2001), classificado no presente estudo como método 2, utiliza, também, os sete dentes mandibulares do lado esquerdo. Atribui-se, então, para cada um destes dentes um estágio de desenvolvimento, classificado de $A$ até $\mathrm{H}$, baseados na mesma representação utilizada no estudo de Demirjian, Goldstein e Tanner (1973) (Figura 2).

Figura 2 - Estágios de desenvolvimento dental segundo Demirjian, Goldstein e Tanner (1973).

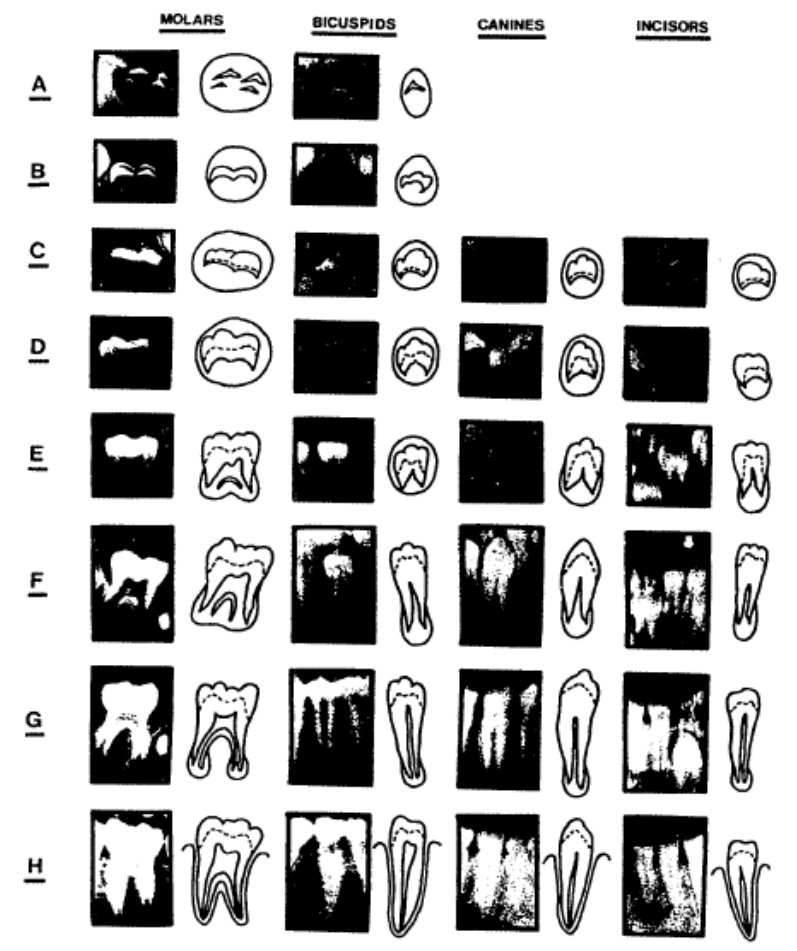

Fonte: Demirjian, Goldstein e Tanner (1973). 
Posteriormente, consulta-se uma tabela que apresenta um score de idade já expresso em anos para cada dente especificamente de acordo com seu respectivo estágio de desenvolvimento, conforme o sexo do indivíduo (Figura 3). Ao final, somase o score dos sete dentes, obtendo-se a idade estimada.

Figura 3 - Tabelas de score para o sexo masculino e feminino, segundo Willems et al. (2001).

\begin{tabular}{|c|c|c|c|c|c|c|c|c|}
\hline \multicolumn{9}{|c|}{$\begin{array}{l}\text { TABLE 1-Developmental tooth stages according to Demirjian's } \\
\text { technique (1) with corresponding age scores expressed directly in years } \\
\text { for each of the seven left mandibular teeth in boys. }\end{array}$} \\
\hline Tooth & A & B & $\mathrm{C}$ & D & $\mathrm{E}$ & $\mathrm{F}$ & G & $\mathrm{H}$ \\
\hline Central incisor & $\ldots$ & $\ldots$ & 1.68 & 1.49 & 1.5 & 1.86 & 2.07 & 2.19 \\
\hline Lateral incisor & $\ldots$ & $\ldots$ & 0.55 & 0.63 & 0.74 & 1.08 & 1.32 & 1.64 \\
\hline Canine & & & & 0.04 & 0.31 & 0.47 & 1.09 & 1.9 \\
\hline First bicuspid & 0.15 & 0.56 & 0.75 & 1.11 & 1.48 & 2.03 & 2.43 & 2.83 \\
\hline Second bicuspid & 0.08 & 0.05 & 0.12 & 0.27 & 0.33 & 0.45 & 0.4 & 1.15 \\
\hline First molar & & & & 0.69 & 1.14 & 1.6 & 1.95 & 2.15 \\
\hline Second molar & 0.18 & 0.48 & 0.71 & 0.8 & 1.31 & 2 & 2.48 & 4.17 \\
\hline \multicolumn{9}{|c|}{$\begin{array}{l}\text { TABLE } 2 \text {-Developmental tooth stages according to Demirjian's } \\
\text { technique (l) with corresponding age scores expressed directly in years } \\
\text { for each of the seven left mandibular teeth in girls. }\end{array}$} \\
\hline Tooth & A & B & C & D & $\mathrm{E}$ & $\mathrm{F}$ & G & $\mathrm{H}$ \\
\hline Central incisor & $\ldots$ & $\ldots$ & 1.83 & 2.19 & 2.34 & 2.82 & 3.19 & 3.14 \\
\hline Lateral incisor & $\ldots$ & $\ldots$ & & 0.29 & 0.32 & 0.49 & 0.79 & 0.7 \\
\hline Canine & $\ldots$ & $\ldots$ & 0.6 & 0.54 & 0.62 & 1.08 & 1.72 & 2 \\
\hline First bicuspid & -0.95 & -0.15 & 0.16 & 0.41 & 0.6 & 1.27 & 1.58 & 2.19 \\
\hline Second bicuspid & -0.19 & 0.01 & 0.27 & 0.17 & 0.35 & 0.35 & 0.55 & 1.51 \\
\hline First molar & $\ldots$ & $\ldots$ & $\ldots$ & 0.62 & 0.9 & 1.56 & 1.82 & 2.21 \\
\hline Second molar & 0.14 & 0.11 & 0.21 & 0.32 & 0.66 & 1.28 & 2.09 & 4.04 \\
\hline
\end{tabular}

Fonte: Willems et al. (2001).

Conforme as classificações do desenvolvimento e medições foram realizadas, os números obtidos eram registrados em uma planilha com a fórmula de Cameriere e Willems já pré-estabelecidas no Microsoft Excel ${ }^{\circledR}$ (Microsoft; Washington, USA). A média entre as idades estimadas por ambos os métodos também foi calculada para observar se a mesma poderia aumentar a correlação com a idade real.

Além de estimar a idade de todas as radiografias panorâmicas, os avaliadores repetiram ambos os métodos em $30 \%$ da amostra após 4 semanas, ou seja, 30 radiografias femininas e 30 radiografias masculinas, para que assim, fosse possível realizar a análise intraobservador. 


\subsection{Análise estatística}

Para a realização de todos os testes da análise estatística, foram utilizados os softwares: $R$ Core Team ( $R$ : A language and environment for statistical computing, $R$ Foundation for Statistical Computing; Vienna, Austria, 2016) e SAS Statistical Software (version 9.3; SAS Institute, Inc. Cary; NC). Assim, foram feitas as análises intraobservador por meio de uma análise exploratória por gráficos tipo Box Plot e, análise de concordância pelo Coeficiente de Correlação Intraclasse (ICC) com seu respectivo Intervalo de Confiança $95 \%$, com o objetivo de verificar se os avaliadores se encontravam calibrados e se os métodos de estimativa de idade eram reprodutíveis.

Foi realizada também uma análise exploratória da amostra em sua totalidade, além da análise de concordância pelo Coeficiente de Correlação Intraclasse (ICC) para verificar se os métodos de Cameriere e Willems, e suas médias, são capazes de produzir valores iguais ou satisfatoriamente semelhantes para a variável "Idade". Já para calcular a concordância e magnitude das diferenças entre as idades reais e as idades estimadas, foi utilizado o método de Bland-Altman e uma regressão linear de efeitos mistos. 
OResultados 


\section{$4 \quad$ RESULTADOS}

\subsection{Análise Intraobservador (Teste Reteste)}

Inicialmente, a fim de verificar a reprodutibilidade dos métodos e a prévia calibração dos avaliadores, foi realizada uma análise exploratória das diferentes estimativas de idade, executadas por cada avaliador em $30 \%$ da amostra feminina e masculina na reavaliação (Teste Reteste), e assim, elaborados gráficos do tipo Box Plot, como representado nas Figuras 4 e 5, respectivamente:

Figura 4 - Gráficos tipo Box Plot da análise Teste Reteste das idades estimadas por cada avaliador para o sexo feminino.
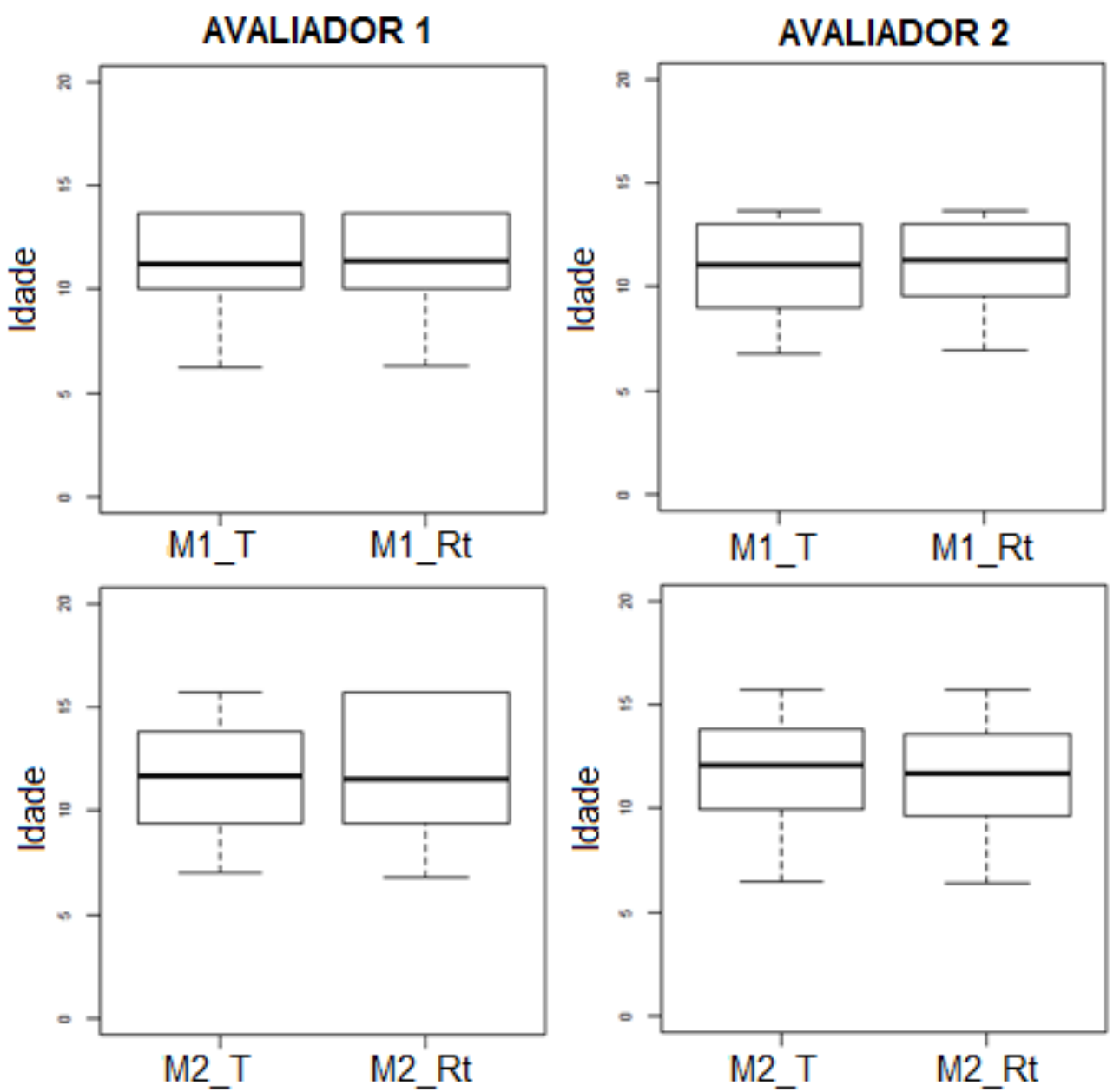

Fonte: Imagem de autoria própria.

M1 - Método 1 (método de Cameriere); M2 - Método 2 (método de Willems); T - Teste; Rt - Reteste. 
Figura 5 - Gráficos tipo Box Plot da análise Teste Reteste das idades estimadas por cada um dos avaliadores para o sexo masculino.
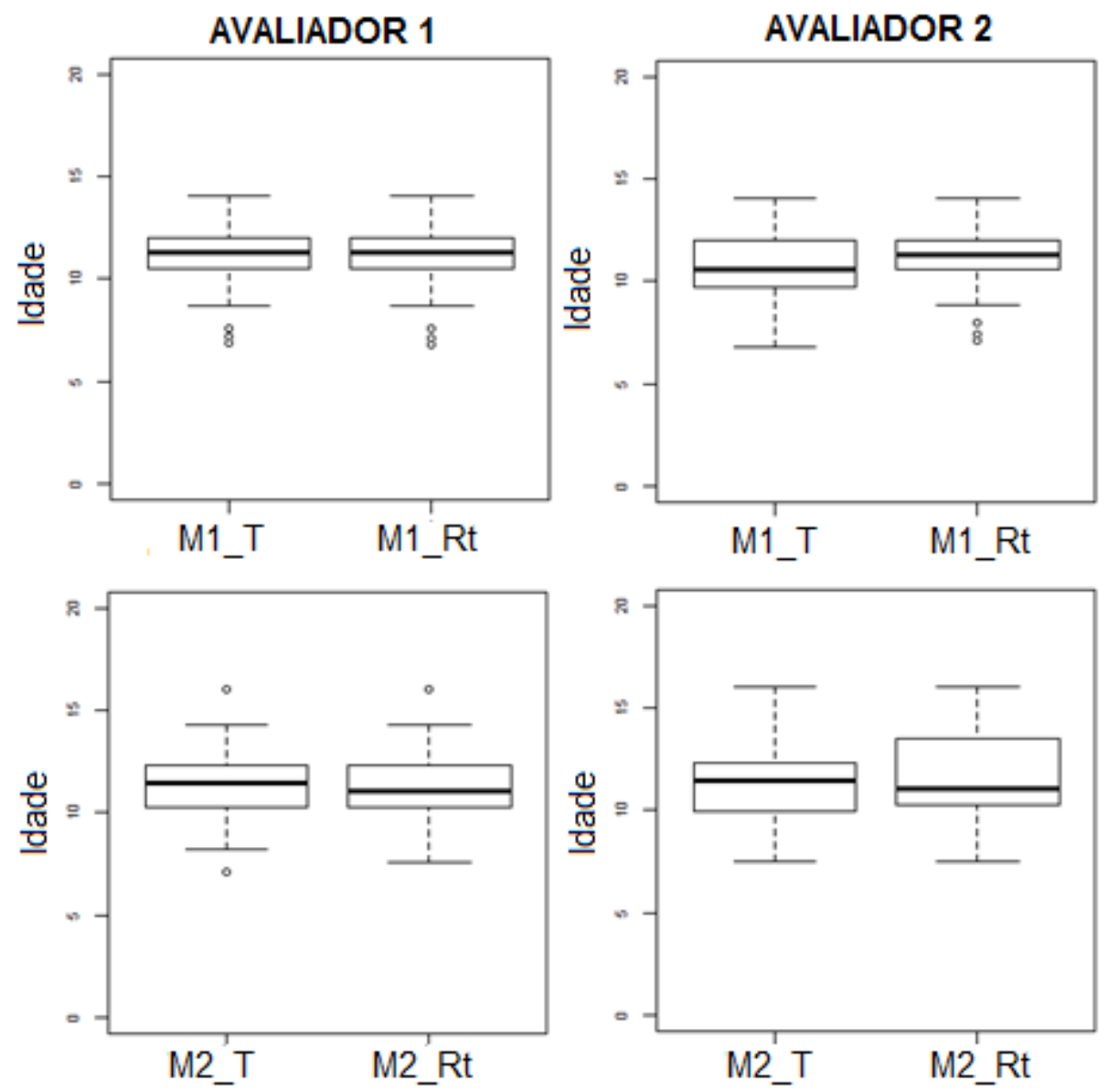

Fonte: Imagem de autoria própria.

M1 - Método 1 (método de Cameriere); M2 - Método 2 (método de Willems); T - Teste; Rt - Reteste.

Após a análise exploratória dos dados de Teste Reteste de 30\% de ambas as amostras, foi calculado o Coeficiente de Correlação Intraclasse (ICC) com seu respectivo Intervalo de Confiança 95\% (Tabela 1), para verificar se as diferentes estimativas de idade realizadas por cada um dos avaliadores são capazes de produzir valores iguais ou satisfatoriamente semelhantes para a variável "Idade", e assim, sugerir a devida calibração dos mesmos. Vale observar que, o ICC quanto mais próximo do valor 1 , maior a correlação entre as idades.

Tabela 1 - Coeficientes de Correlação Intraclasse (ICC) dos dados de Teste Reteste para cada avaliador por ambos os métodos e sexos.

\begin{tabular}{cccc}
\hline SEXO & AVALIADOR & ICC MÉTODO 1 & ICC MÉTODO 2 \\
\hline \multirow{2}{*}{ Feminino } & 1 & $0.99(0.98 ; 1)$ & $0.98(0.95 ; 0.99)$ \\
& 2 & $0.98(0.95 ; 0.99)$ & $0.96(0.92 ; 0.98)$ \\
Masculino & 1 & $1(0.99 ; 1)$ & $0.99(0.98 ; 0.99)$ \\
& 2 & $0.94(0.78 ; 0.98)$ & $0.95(0.91 ; 0.98)$ \\
\hline
\end{tabular}

Fonte: Tabela de autoria própria.

Método 1 - método de Cameriere; Método 2 - método de Willems. 
Da mesma forma, foram elaborados gráficos com as idades estimadas no Teste e Reteste por ambos avaliadores e métodos, tanto para o sexo feminino (Figura 6) como masculino (Figura 7), sendo o eixo $\mathrm{X}$ representando as idades estimadas no Teste (T) e o eixo Y, no Reteste (Rt).

Figura 6 - Coeficiente de Correlação Intraclasse (ICC) das idades estimadas por ambos os métodos e avaliadores no Teste Reteste, para o sexo feminino.
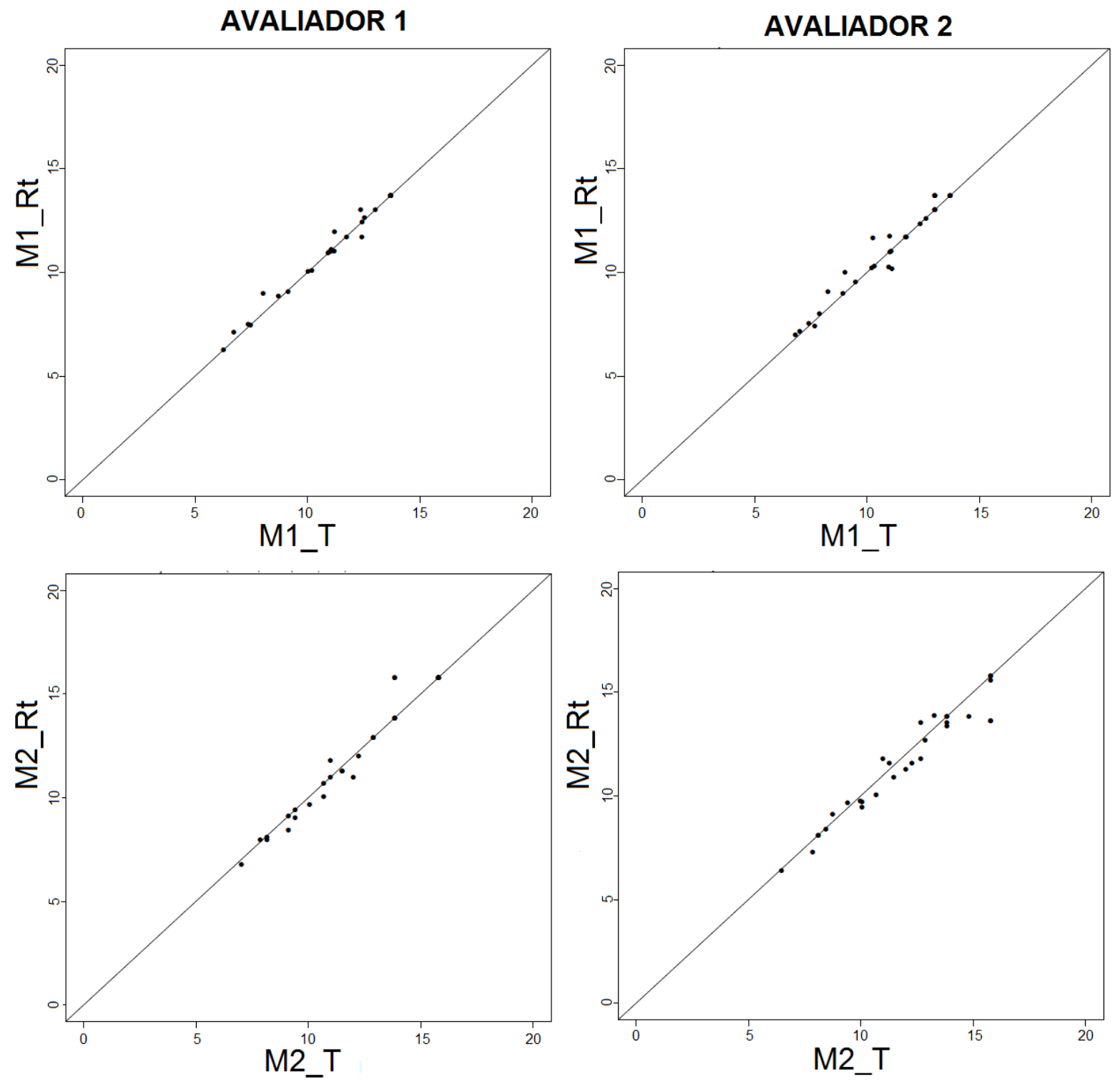

Fonte: Imagem de autoria própria.

M1 - Método 1 (método de Cameriere); M2 - Método 2 (método de Willems); T - Teste; Rt - Reteste. 
Figura 7 - Coeficiente de Correlação Intraclasse (ICC) das idades estimadas por ambos os métodos e avaliadores no Teste Reteste, para o sexo masculino.

\section{AVALIADOR 1}
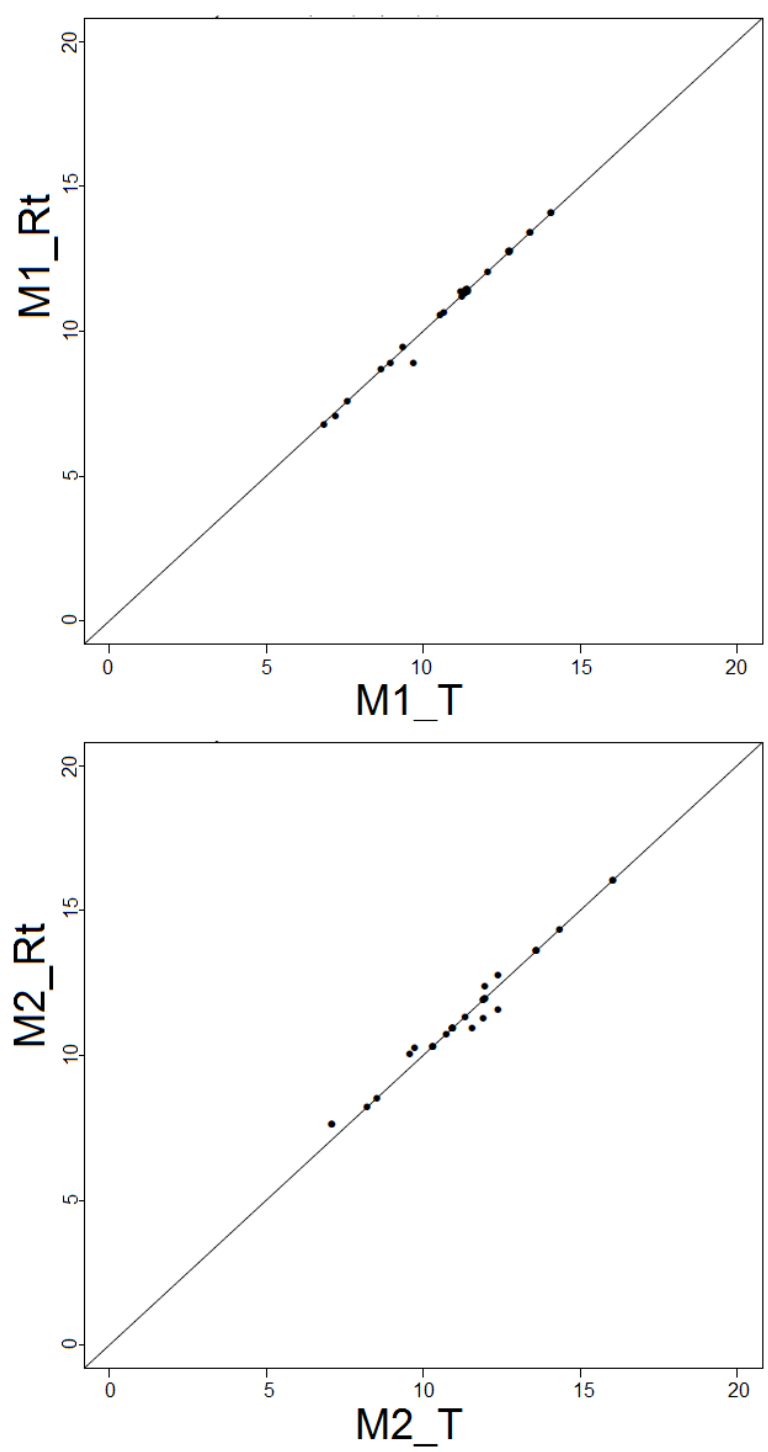

AVALIADOR 2
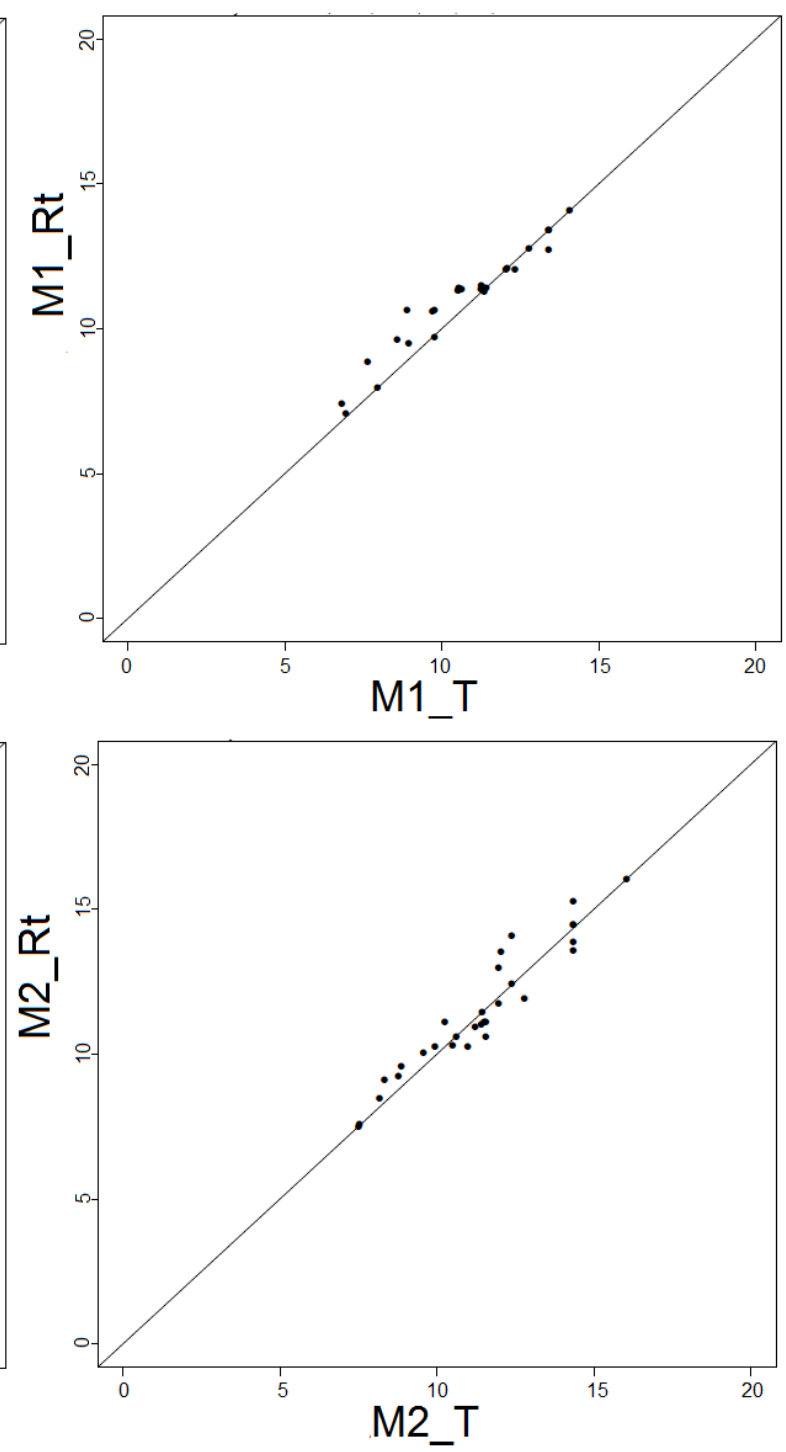

Fonte: Imagem de autoria própria.

M1 - Método 1 (método de Cameriere); M2 - Método 2 (método de Willems); T - Teste; Rt - Reteste.

Considerando que os Coeficientes de Correlação Intraclasse (ICC) se aproximaram do valor 1 , com seus respectivos intervalos de confiança $95 \%$, sendo o mínimo 0,94 e o máximo 1, fica evidenciado uma grande correlação entre as idades estimadas por cada avaliador no Teste e no Reteste, ou seja, o métodos utilizados são reprodutíveis e os avaliadores se apresentavam devidamente calibrados. Assim, após a análise intraobservador, deu-se início às análises das amostras em sua totalidade a fim de verificar a concordância entre as idades reais e estimadas. 


\subsection{Análise Exploratória}

Para realizar uma análise inicial exploratória da amostra em sua totalidade, foram elaborados gráficos do tipo Box Plot a fim de verificar os quartis, máximo, mínimo e mediana das idades reais e estimadas para o sexo feminino e masculino por cada avaliador e por ambos os métodos, assim como a média entre eles. As figuras a seguir representam as idades estimadas por ambos os avaliadores para o sexo feminino e masculino, respectivamente:

Figura 8 - Gráficos tipo Box Plot das idades reais e estimadas por ambos os métodos, assim como suas médias, para o sexo feminino.

AVALIADOR 1

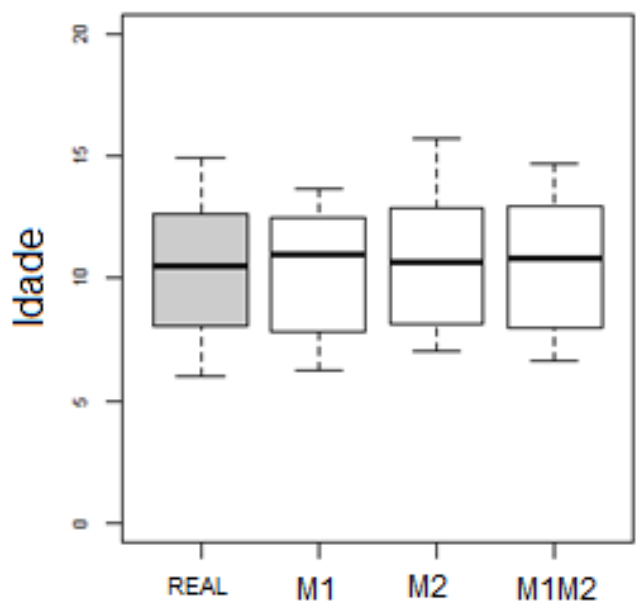

AVALIADOR 2

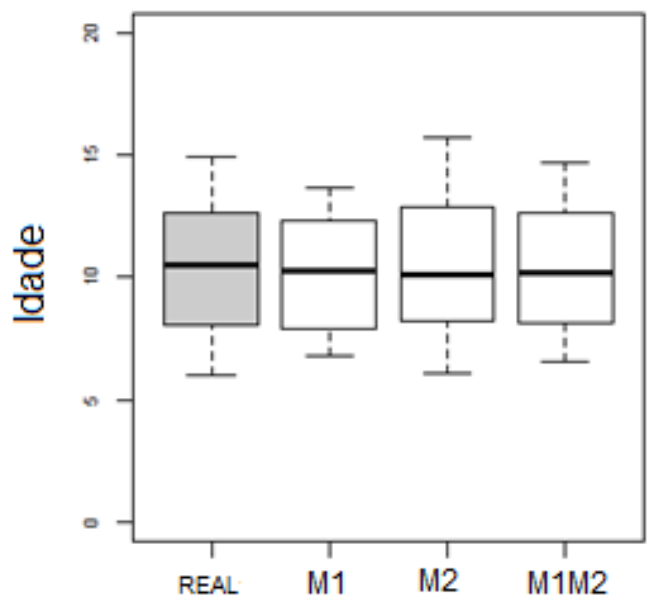

Fonte: Imagem de autoria própria.

M1 - Método 1 (método de Cameriere); M2 - Método 2 (método de Willems); M1M2 - Média entre o método 1 e 2.

Figura 9 - Gráficos tipo Box Plot das idades reais e estimadas por ambos os métodos, assim como suas médias, para o sexo masculino.

AVALIADOR 1

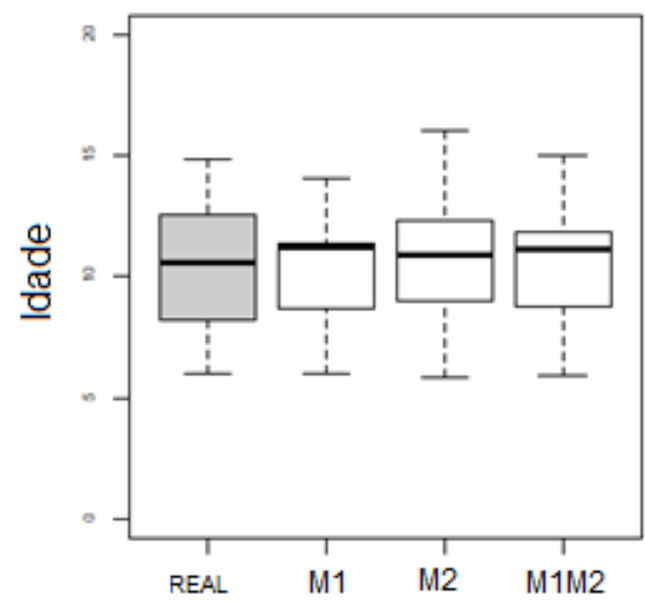

AVALIADOR 2

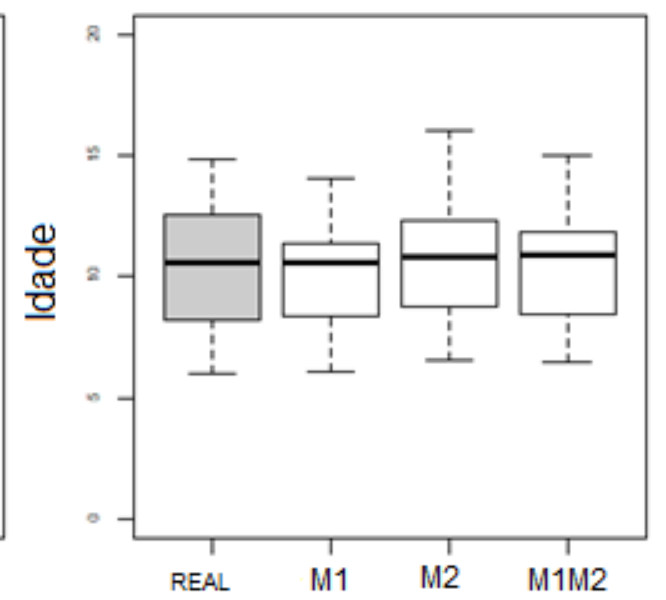

Fonte: Imagem de autoria própria.

M1 - Método 1 (método de Cameriere); M2 - Método 2 (método de Willems); M1M2 - Média entre o método 1 e 2. 


\subsection{Concordância entre idades reais e estimadas pelo ICC}

Com o objetivo de avaliar se os métodos de estimativa de idade são capazes de produzir valores iguais ou satisfatoriamente semelhantes para a variável "Idade", foi calculado o Coeficiente de Correlação Intraclasse (ICC) com seu respectivo Intervalo de Confiança 95\%. Além do ICC para cada método utilizado, também foi calculado o ICC para a média entre as idades estimadas pelo método 1 e 2 , conforme observado na Tabela 2:

Tabela 2 - Coeficientes de Correlação Intraclasse (ICC) entre as idades reais e idades estimadas do sexo feminino e masculino por ambos os avaliadores e métodos, assim como a média entre eles.

\begin{tabular}{ccccc}
\hline SEXO & AVALIADOR & ICC MÉTODO 1 & ICC MÉTODO 2 & ICC MÉDIA \\
\hline \multirow{2}{*}{ Feminino } & 1 & $0.94(0.92 ; 0.96)$ & $0.94(0.79 ; 0.98)$ & $0.96(0.92 ; 0.98)$ \\
& 2 & $0.93(0.9 ; 0.96)$ & $0.94(0.89 ; 0.97)$ & $0.96(0.94 ; 0.97)$ \\
Masculino & 1 & $0.92(0.88 ; 0.95)$ & $0.94(0.85 ; 0.97)$ & $0.94(0.91 ; 0.96)$ \\
& 2 & $0.93(0.89 ; 0.95)$ & $0.94(0.89 ; 0.96)$ & $0.95(0.92 ; 0.96)$ \\
\hline
\end{tabular}

Fonte: Tabela de autoria própria.

Método 1 - método de Cameriere; Método 2 - método de Willems.

Da mesma forma, foram elaborados gráficos para ambos avaliadores e métodos utilizados, tanto para o sexo feminino (Figura 10) quanto masculino (Figura 11), assim como, a média entre as idades estimadas pelo método de Cameriere e Willems, sendo o eixo $\mathrm{X}$ representando as idades estimadas e o eixo $\mathrm{Y}$, as idades reais dos indivíduos. 
Figura 10 - Coeficiente de Correlação Intraclasse (ICC) entre as idades reais e as idades estimadas por ambos os métodos, assim como suas médias, para o sexo feminino.
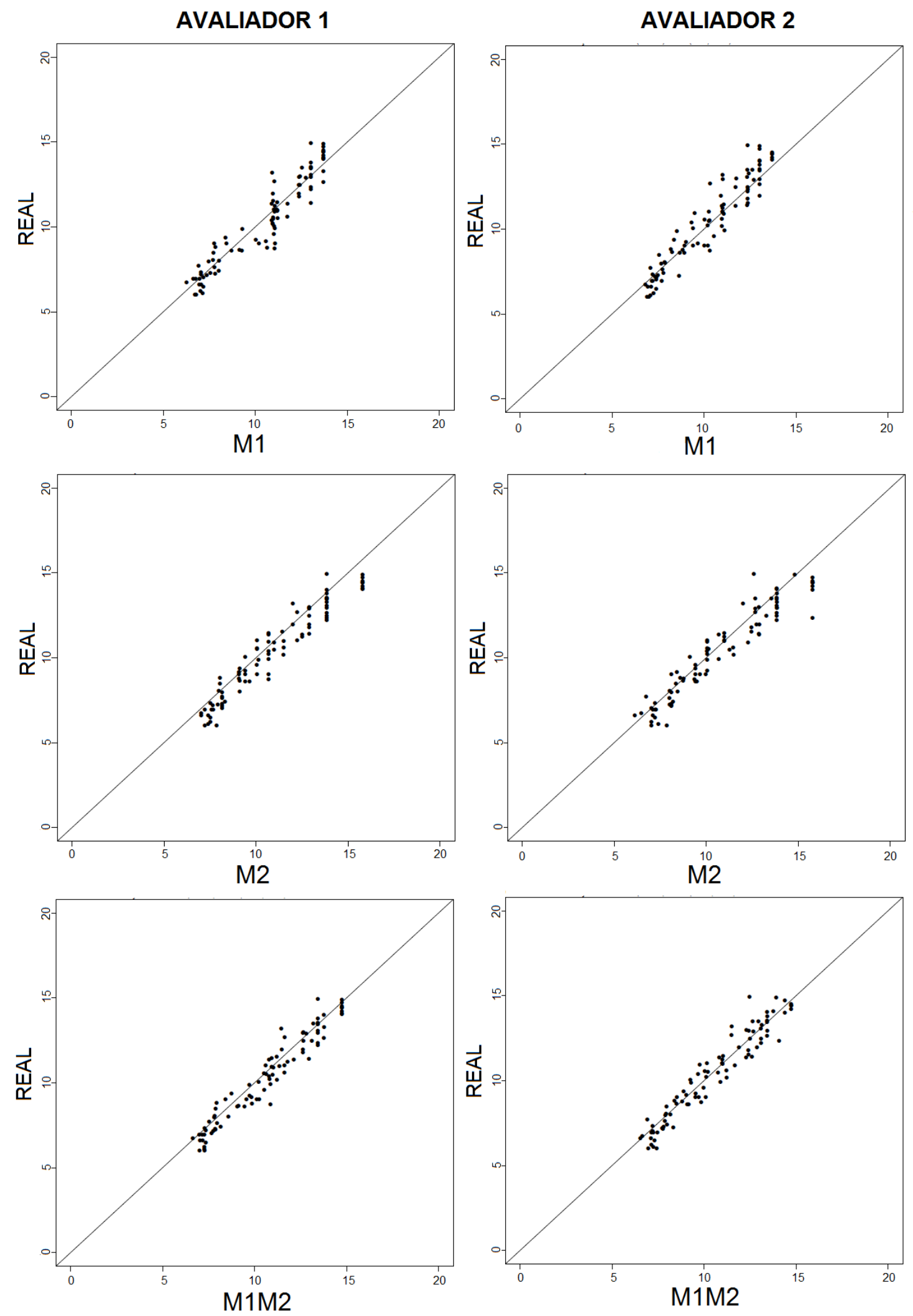

Fonte: Imagem de autoria própria.

M1 - Método 1 (método de Cameriere); M2 - Método 2 (método de Willems); M1M2 - Média entre o método 1 e 2. 
Figura 11 - Coeficiente de Correlação Intraclasse (ICC) entre as idades reais e as idades estimadas por ambos os métodos, assim como suas médias, para o sexo masculino.
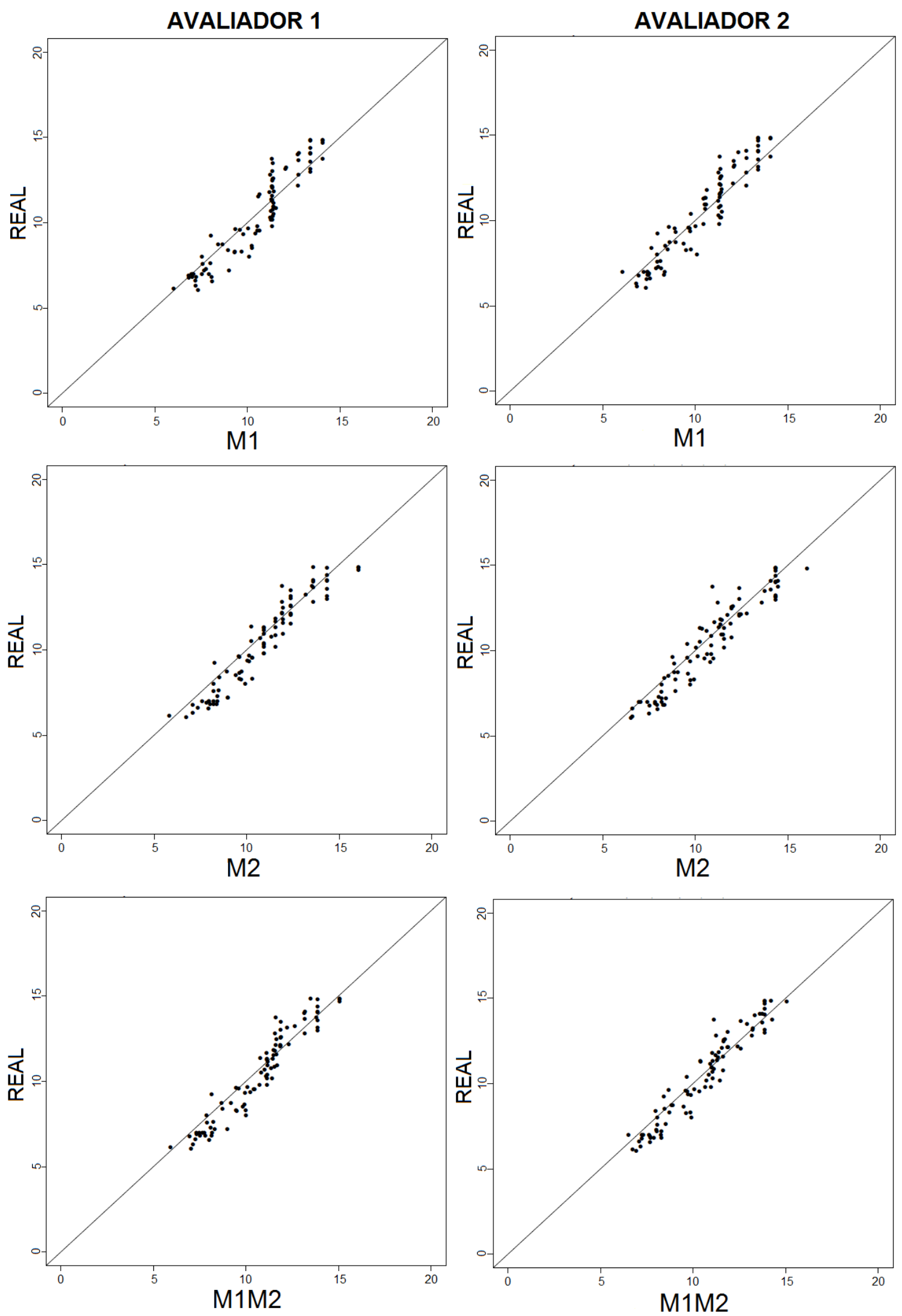

Fonte: Imagem de autoria própria.

M1 - Método 1 (método de Cameriere); M2 - Método 2 (método de Willems); M1M2 - Média entre o método 1 e 2. 
Os valores do Coeficiente de Correlação Intraclasse (ICC) para ambos os sexos e métodos se aproximam do valor 1 , sendo 0,92 o valor mínimo encontrado, sugerindo que, tanto o método de Cameriere quanto o método de Willems, são capazes de produzir valores iguais ou satisfatoriamente semelhantes para a variável "Idade". Além disso, o Coeficiente de Correlação Intraclasse (ICC) se apresentou maior quando realizada a média entre os métodos utilizados.

\subsection{Concordância entre as idades reais e estimadas pelo gráfico de Bland- Altman}

A fim de calcular a diferença entre as idades reais dos indivíduos e as idades obtidas por cada um dos métodos, foram elaborados gráficos do tipo Bland-Altman, o qual se apresenta como um procedimento estatístico de análise gráfica para comparação de dois métodos (no caso, método 1 ou 2 e a idade real), usados para mensuração de variáveis contínuas. Procede-se da seguinte forma: calcula-se a diferença entre as medidas obtidas pelos dois métodos e a média e o desvio padrão dessas diferenças. A linha central é a média das diferenças observadas entre as duas medidas, e assim, espera-se que medidas concordantes tenham valores da diferença situados próximos de zero. Dessa forma, foram elaborados gráficos para o sexo feminino (Figura 12) e para o sexo masculino (Figura 13), segundo cada avaliador e método utilizado, assim como, para as médias entre as idades estimadas pelo método de Cameriere e Willems. 
Figura 12 - Diferença entre as idades reais e as idades estimadas por ambos os métodos, assim como suas médias, para o sexo feminino.
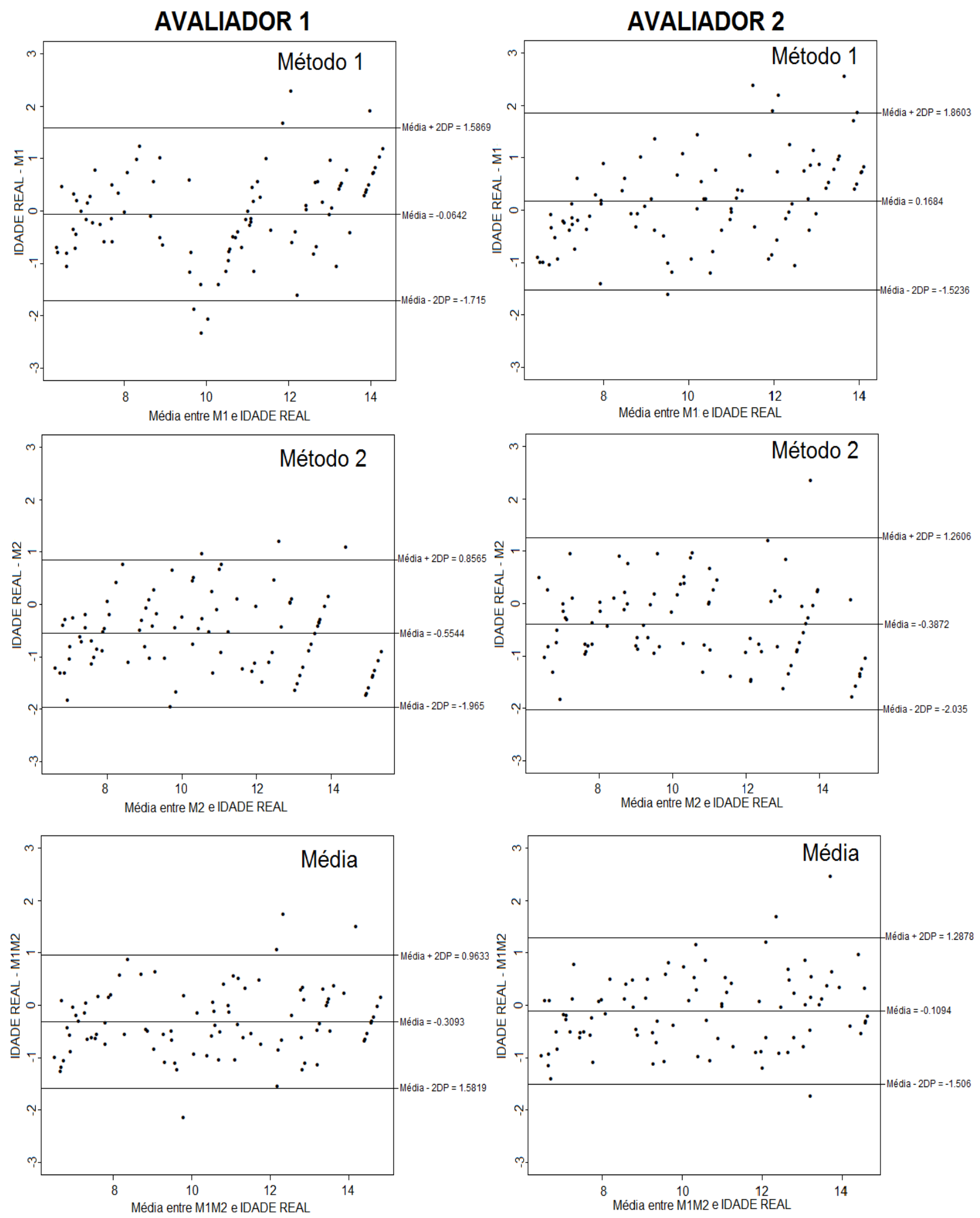

Fonte: Imagem de autoria própria.

M1 - Método 1 (método de Cameriere); M2 - Método 2 (método de Willems); M1M2 - Média entre o método 1 e 2 . 
Figura 13 - Diferença entre as idades reais e as idades estimadas por ambos os métodos, assim como suas médias, para o sexo masculino.
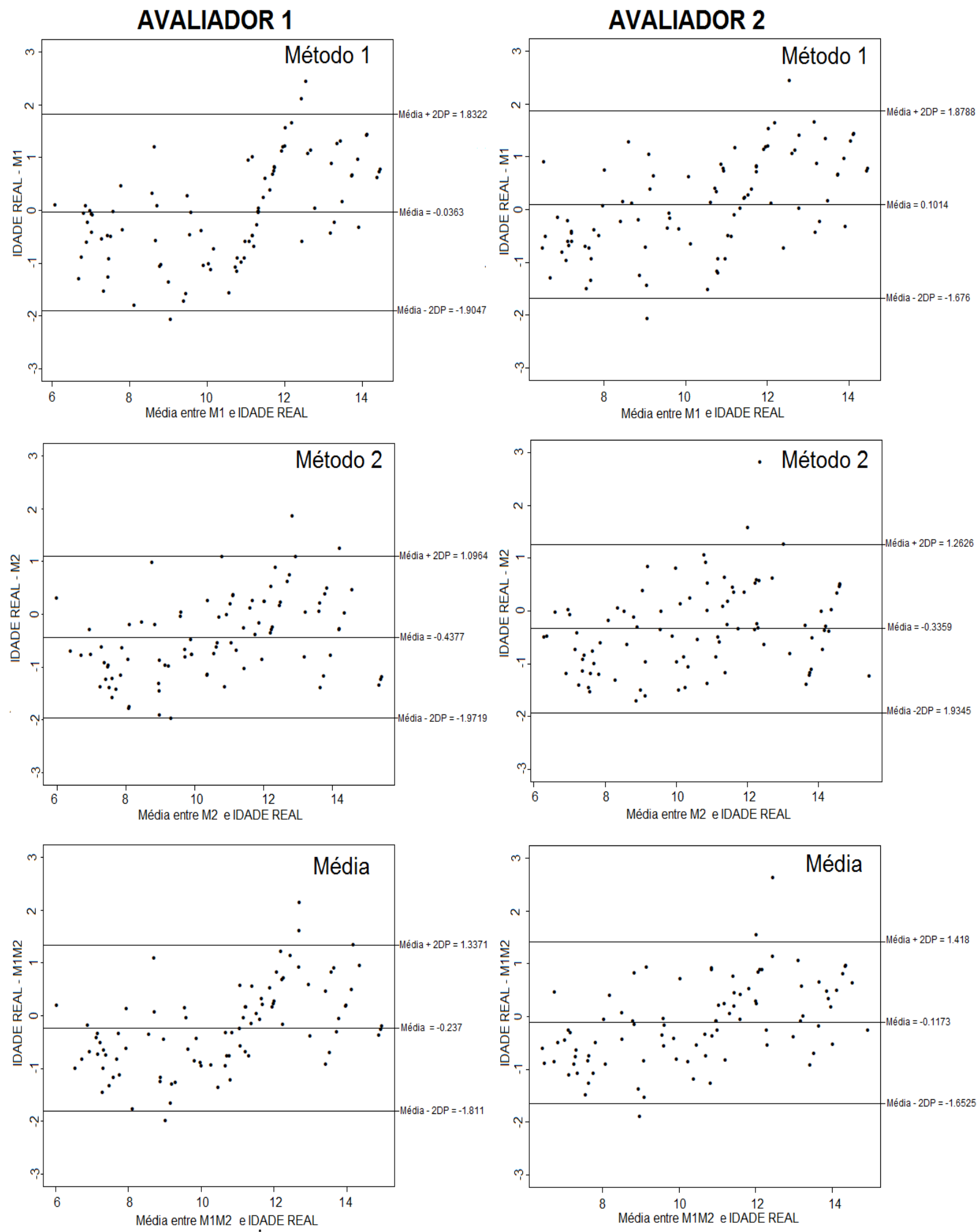

Fonte: Imagem de autoria própria.

M1 - Método 1 (método de Cameriere); M2 - Método 2 (método de Willems); M1M2 - Média entre o método 1 e 2. 
Por meio das imagens apresentadas acima, é possível observar que os gráficos que representam a diferença entre a idade real e o método 2 (método de Willems) possuem a linha central com uma tendência a maiores valores negativos, circunstância que demonstra uma superestimação de idade pelo método para ambos os sexos, visto que tal diferença é calculada a partir da idade real. Tal fato não é evidenciado no método 1 (método de Cameriere), onde a linha central se situa mais próxima ao valor zero, demonstrando menor diferença com a idade real.

\subsection{Comparação entre as idades reais e estimadas}

Visando comparar a idade real e as idades estimadas de forma geral, considerando o efeito aleatório por indivíduo, foi utilizado um modelo de regressão linear com efeitos mistos para a análise das variáveis. Assim, são apresentadas as diferenças estimadas com seus respectivos valores p e intervalos de confiança 95\%. Intervalos de confiança que não englobam o valor zero, trazem evidências de diferenças entre os grupos e, seus limites mostram a magnitude desta diferença. Já os intervalos de confiança que englobam o valor zero, não trazem evidências de diferença entre as idades reais e as idades estimadas. Assim, a Tabela 3 compara a idade real com a idade estimada de cada método em cada avaliador com seus valores p e intervalos de confiança 95\%. Da mesma forma, a Tabela 4 compara a idade real com a idade estimada de cada método, contudo, sem separação por avaliador.

Tabela 3 - Comparação entre idade real e estimada de cada método para cada avaliador.

\begin{tabular}{ccccccc}
\hline \multirow{2}{*}{ SEXO } & \multirow{2}{*}{ COMPARAÇÃO } & DIFERENÇA & VALOR & \multicolumn{2}{c}{ INTERVALO DE CONFIANÇA 95\% } \\
\cline { 6 - 7 } & & ESTIMADA & $\mathbf{p}$ & LIMITE INFERIOR & LIMITE SUPERIOR \\
\hline \multirow{6}{*}{ Feminino } & Idade Real & M1AV1 & $-0,06$ & 0,3851 & $-0,21$ & 0,08 \\
& Idade Real & M2AV1 & $-0,55$ & 0,0001 & $-0,70$ & $-0,41$ \\
& Idade Real & M1M2AV1 & $-0,31$ & 0,0001 & $-0,45$ & $-0,16$ \\
& Idade Real & M1AV2 & 0,17 & 0,0230 & 0,02 & $-0,31$ \\
& Idade Real & M2AV2 & $-0,39$ & 0,0001 & $-0,53$ & 0,04 \\
\hline \multirow{6}{*}{ Masculino } & Idade Real & M1M2AV2 & $-0,11$ & 0,1389 & $-0,25$ & 0,10 \\
& Idade Real & M1M2AV1 & $-0,24$ & 0,0007 & $-0,37$ & $-0,30$ \\
& Idade Real & M1AV1 & $-0,04$ & 0,6015 & $-0,17$ & $-0,10$ \\
& Idade Real & IdaV2 & 0,10 & 0,1445 & $-0,03$ & 0,24 \\
& Idade Real & M2AV2 & $-0,34$ & 0,0001 & $-0,47$ & $-0,20$ \\
& Idade Real & M1M2AV2 & $-0,12$ & 0,0915 & $-0,25$ & 0,02 \\
\hline
\end{tabular}

Fonte: Tabela de autoria própria.

M1 - Método 1 (método de Cameriere); M2 - Método 2 (método de Willems); M1M2 - Média entre o método 1 e 2; AV1 - Avaliador 1; AV2 - Avaliador 2. 
Tabela 4 - Comparação entre idade real e estimada de cada método.

\begin{tabular}{ccccccc}
\hline \multirow{2}{*}{ SEXO } & \multirow{2}{*}{ COMPARAÇÃO } & DIFERENÇA & VALOR & \multicolumn{2}{c}{ INTERVALO DE CONFIANÇA 95\% } \\
\cline { 6 - 7 } & & ESTIMADA & $\mathbf{p}$ & LIMITE INFERIOR & LIMITE SUPERIOR \\
\hline \multirow{3}{*}{ Feminino } & Idade Real & M1 & 0,05 & 0,4239 & $-0,08$ & 0,18 \\
& Idade Real & M2 & $-0,47$ & 0,0001 & $-0,60$ & $-0,34$ \\
& Idade Real & M1M2 & $-0,21$ & 0,0014 & $-0,34$ & $-0,08$ \\
\hline \multirow{3}{*}{ Masculino } & Idade Real & M1 & 0,03 & 0,5901 & $-0,09$ & 0,15 \\
& Idade Real & M2 & $-0,39$ & 0,0001 & $-0,51$ & $-0,27$ \\
& Idade Real & M1M2 & $-0,18$ & 0,0035 & $-0,30$ & $-0,06$ \\
\hline
\end{tabular}

Fonte: Tabela de autoria própria.

M1 - Método 1 (método de Cameriere); M2 - Método 2 (método de Willems); M1M2 - Média entre o método 1 e 2 .

Dessa forma, é possível observar que as diferenças estimadas para o método 1 (método de Cameriere) se apresentam positivas e próximas a zero, demonstrando uma leve subestimação e pequena diferença entre as idades reais e estimadas. A diferença estimada para o método 2 (método de Willems) se apresenta em valores negativos e mais distantes do valor 0 , evidenciando uma superestimação e maior diferença entre as idades reais e estimadas pelo método.

Em relação ao intervalo de confiança e ao valor $p$, o método de Cameriere engloba o valor zero em ambos os sexos e possui pouca distância entre seus limites superiores e inferiores, além de apresentar um valor $p$ maior que 0,05 , ou seja, não trazem evidências de diferenças estatísticas entre as idades reais e as idades estimadas. Já para o método de Willems, o intervalo de confiança mostra-se negativo, não englobando o valor zero, trazendo evidências de diferenças estatísticas entre as idades reais e as idades estimadas.

Sabendo disso, é possível notar a influência do método de Willems na superestimação da média calculada entre ambos os métodos, pois mesmo com intervalos de confiança mais próximos de zero e menor valor $p$, as diferenças estimadas ainda se mantiveram em número negativos. Apesar dos Coeficientes de Correlação Intraclasse (ICC) das médias se apresentarem mais próximos ao valor 1, é possível notar a superestimação em relação à idade real. 


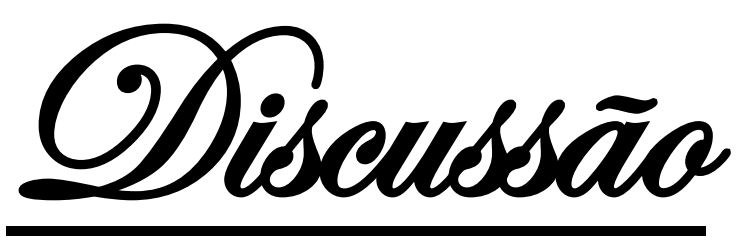




\section{DISCUSSÃO}

Estudos têm demonstrado rapidez e confiabilidade na utilização de radiografias panorâmicas no processo de estimativa de idade dental, visto que esse tipo de exame de imagem possui grande facilidade de realização, principalmente quando se trata de indivíduos ainda na fase infantil, dado a dificuldade de tomadas radiográficas intraorais sem que haja grandes distorções. Além disso, esse tipo de radiografia apresenta aceitáveis distorções quando corretamente realizado e proporciona ampla visualização dos elementos dentais e das estruturas ósseas adjacentes, permitindo a observação tanto do grau de desenvolvimento, quanto de erupção dental (ELBAKARI; HAMMAD; MOHAMMED, 2010; MANI et al., 2008; SALIBA et al., 1997; SATO et al., 2005).

É notório que a análise do grau de desenvolvimento dental traz maior confiabilidade quando comparado ao grau de erupção, visto os inúmeros fatores ambientais e exógenos que possuem influência sobre esta última categoria, como as ausências ou perdas precoces de elementos dentais que podem acelerar ou retardar a erupção dental e também, as anquiloses, caracterizadas como uma fusão anatômica entre a raiz do dente e a estrutura óssea alveolar (GOUVEIA, 2016; JAVADINEJAD; SEKHAVATI; GHAFARI, 2015).

Entretanto, mesmo não sendo influenciado por fatores exógenos, como ocorre na erupção, o grau de desenvolvimento dental se mostra diferente entre as diversas localidades e regiões, pois há distintas características genéticas e socioeconômicas entre os grupos populacionais, trazendo assim, uma impossibilidade de aplicação indiscriminada dos métodos de estimativa de idade (EL-BAKARI; HAMMAD; MOHAMMED, 2010; FREITAS et al., 1990).

Quando se remete ao território brasileiro, a heterogeneidade é facilmente perceptível, visto a miscigenação entre os ameríndios, europeus e africanos subsaarianos no início da colonização do país, fato que proporciona grandes polimorfismos genéticos e discrepâncias dentro da própria população, tornando necessária a realização de diversos estudos para abranger as regiões brasileiras em sua totalidade (KURITA, 2004; SUAREZ-KURTZ, 2009).

Isto posto, é fundamental que a aplicabilidade do método de escolha já tenha sido avaliada na população que se deseja utilizar, e se necessário, estabelecer fatores de correção para a utilização do mesmo (KURITA, 2004). Ademais, previamente à 
estimativa de idade em grandes amostras, é fundamental que haja a calibração dos diferentes avaliadores para analisar a capacidade do método em ser reprodutível, melhorar constantemente a qualidade dos procedimentos e assim, buscar a padronização nas avaliações (OLIVEIRA, 2010).

No presente estudo, é possível observar expressivos valores de correlação entre a primeira (Teste) e segunda (Reteste) avaliação para estimar a idade, sendo o Coeficiente de Correlação Intraclasse (ICC) mínimo de 0,94 e máximo de 1, valores que sugerem a reprodutibilidade dos métodos de Willems e Cameriere, além da devida calibração entre os avaliadores.

A correlação positiva entre 0 teste e reteste dos dois métodos também foi demonstrada no estudo de El-Bakary, Hammad e Mohammed (2010), os quais reexaminaram uma amostra aleatória de 50 radiografias panorâmicas após duas semanas, resultando em uma análise intraobservador com um coeficiente Alfa de Cronbach de 0,91, sugerindo também, a confiabilidade dos métodos.

Já Fernandes et al. (2011) analisaram apenas o método de Cameriere, reavaliando 20 radiografias panorâmicas para a análise intraobservador, a qual resultou em um valor $p$ de 0,315 para o primeiro avaliador e de 0,193 para o segundo avaliador, demonstrando que não houve evidências de diferença entre o teste e o reteste. Semelhantemente, Galic et al. (2011) analisaram a reprodutibilidade do método de Willems, reexaminando $10 \%$ de sua amostra, e assim, realizaram a análise intraobservador que resultou em um Coeficiente de Concordância de Kappa no valor de 0,811 , demonstrando que este método também é reprodutível.

Quanto à diferença dos valores de reprodutibilidade entre ambos os métodos, é possível observar que não houve grandes discrepâncias estatísticas. Essa condição deve-se ao fato de que o método de Willems se baseia nos estágios de desenvolvimento do estudo de Dermijian, Goldstein e Tanner (1973). Apesar de ser um método qualitativo, o qual se caracteriza por ser subjetivo, interpretativo e descritivo, os estágios desenvolvidos por Dermijian são claramente definidos e com poucos estágios intermediários, facilitando a classificação do desenvolvimento de cada elemento dental (CASTRO, 2017; OLIVEIRA, 2010).

Outro fato que aproxima a alta reprodutibilidade dos dois métodos é a característica quantitativa do método de Cameriere, o qual é fundamentado em medidas e fórmulas matemáticas, ou seja, apresenta uma abordagem objetiva, estatística e numérica que minimiza os possíveis erros de interpretação, depositando 
maior confiabilidade no mesmo (CASTRO, 2017; EL-BAKARI; HAMMAD; MOHAMMED, 2010).

Ainda que um método seja qualitativo e o outro, quantitativo, há um aspecto comum entre os dois métodos: a utilização dos elementos dentais localizados no quadrante inferior esquerdo. A preferência por essa região se dá por dois principais motivos, primeiramente porque os dentes inferiores possuem maior facilidade de visualização na radiografia panorâmica quando comparados aos dentes superiores (KURITA, 2004), já a preferência pelo lado esquerdo mostra-se para fins de padronização, uma vez que Dermijian, Goldstein e Tanner (1973) relataram que o valor estimado para os sete dentes inferiores esquerdos representariam todo 0 arco dental inferior.

Entretanto, diversos estudos demonstram que não há diferenças significantes entre as fases de mineralização dos dentes do lado esquerdo e direito, como Nolla (1960) que buscou estudar o desenvolvimento da dentição permanente desde o início até o final da calcificação dental, e Araújo (2000), o qual analisou 334 radiografias panorâmicas a fim de avaliar os diferentes estágios de mineralização, considerando assim, o lado esquerdo apenas para fins de padronização.

Com isso, há relatos de estudos que substituíram os dentes que estavam ausentes no lado esquerdo do arco dental, por elementos dentais do lado direito, como Bagic et al. (2008) que estimaram a idade por meio de 324 imagens radiográficas, excluindo apenas aquelas que apresentaram ausências bilaterais dos primeiros molares inferiores, pois se houvesse a ausência desse elemento dental apenas no hemiarco esquerdo, o mesmo seria substituído pelo contralateral.

Posteriormente à calibração e aplicação de ambos os métodos no presente estudo, foi possível observar altos valores de correlação entre as idades reais e as idades estimadas em sua totalidade amostral, onde a correlação mínima para o método de Cameriere foi de 0,92 e a máxima de 0,94. Já para o método de Willems, a correlação se apresentou em 0,94 para ambos os sexos e avaliadores, considerando - Coeficiente de Correlação Intraclasse (ICC) com seu respectivo Intervalo de Confiança $95 \%$.

Dessa forma, averígua-se que ambos os métodos de estimativa de idade demonstram significativa aplicabilidade na amostra estudada. Além disso, a média das idades estimadas pelo método de Cameriere e Willems indica um aumento máximo de 0,03 no Coeficiente de Correlação Intraclasse (ICC). 
Já em relação aos diferentes valores de correlação entre os métodos, nota-se que o método de Willems se mostrou ligeiramente superior aos valores correspondentes ao método de Cameriere. Essa diferença se assemelha ao estudo de El-Bakary, Hammad e Mohammed (2010), os quais estimaram a idade por meio de 286 radiografias panorâmicas de indivíduos egípcios de 5 a 16 anos, e assim, obtiveram $98,62 \%$ de acurácia com o método de Willems e $98,02 \%$ com o método de Cameriere.

Semelhantemente, Rai e Anand (2006), por meio de um estudo com 75 radiografias panorâmicas de indivíduos indianos de 5 a 14 anos, também concluíram que o método de Willems possui uma maior acurácia em relação ao método de Cameriere. Esta ligeira diferença, presente nos estudos supracitados, pode ser explicada pelo número amostral utilizado por Cameriere, Ferrante e Cingolani (2006) em seu estudo, os quais utilizaram 455 radiografias panorâmicas de indivíduos italianos de cinco a 15 anos de idade. Tal número amostral se difere da pesquisa de Willems et al. (2001), realizada com 2523 radiografias panorâmicas de uma população caucasiana belga. Além disso, o método elaborado por Cameriere, Ferrante e Cingolani (2006) envolve mais etapas de medidas e cálculos, exigindo assim, treinamento e experiência do avaliador por estar associado a uma curva de aprendizagem mais longa (EL-BAKARI; HAMMAD; MOHAMMED, 2010; GOUVEIA, 2016).

Já no estudo de Galic et al. (2011), realizado com radiografias panorâmicas de uma comunidade da Bósnia e Herzegovina, fica evidenciado a maior acurácia do método de Cameriere quando comparado ao método de Willems, resultado que sugere a necessidade de estabelecer fatores de correção e melhorar a adaptação do método qualitativo para a população estudada.

Apesar do maior Coeficiente de Correlação Intraclasse apresentado no método de Willems, o mesmo apontou uma superestimação da idade frente à idade real dos indivíduos, circunstância que pode ser observada pelos resultados negativos das diferenças estimadas. A diferença para o método de Willems resultou em um valor de $-0,47$ para o sexo feminino e $-0,39$ para o sexo masculino. Além disso, o valor $p$ se encontra em um valor menor que 0,05 e o intervalo de confiança não engloba o valor zero, trazendo evidências de diferenças entre as idades reais e as idades estimadas quando as mesmas são comparadas diretamente. 
Essa diferença negativa observada no método supracitado fica claramente demonstrada nos gráficos do Coeficiente de Correlação Intraclasse (ICC), visto que, apesar dos valores se situarem próximos à linha oblíqua central, eles possuem a tendência de se localizar à direita da mesma, já que as idades estimadas estão localizadas no eixo $\mathrm{X}$ e as reais, no eixo $\mathrm{Y}$.

A superestimação da idade apresentada pelo método de Willems se deve ao estudo em que foi baseado. Willems et al. (2001) simplificaram as duas tabelas de score, criadas por Dermijian, Goldstein e Tanner (1973), para uma única tabela que corresponde diretamente à estimativa de idade, além de adaptar o sistema de pontuação para a população caucasiana belga. Entretanto, ambos os métodos possuem diversos relatos na literatura de superestimação em diferentes populações (EL-BAKARI; HAMMAD; MOHAMMED, 2010; FRANCO et al., 2013; GALIC et al., 2011).

Na comunidade da Bósnia e Herzegovina, Galic et al. (2011) demonstraram uma superestimação da idade de 0,25 para as meninas e de 0,42 para o sexo masculino. Da mesma forma, por meio de uma amostra egípcia, El-Bakary, Hammad e Mohammed (2010) concluíram que o método de Willems superestimou em 0,14 $\pm 0,74$ anos para as meninas e $0,29 \pm 0,48$ para os meninos. Mesmo na população brasileira, há estudos que apresentam tal característica, como Franco et al. (2013) que indicaram uma diferença de 0,78 para o sexo feminino e 0,81 para o sexo masculino.

Já para o método de Cameriere, há uma melhor distribuição das idades estimadas em torno das idades reais. Apesar dos valores se situarem mais afastados da linha oblíqua central nos gráficos de Coeficiente de Correlação Intraclasse (ICC), quando comparado aos gráficos do método de Willems, os mesmos se encontram dispostos mais uniformemente ao redor da linha supracitada. Esse resultado também fica demonstrado pelo baixo valor das diferenças entre as idades reais e estimadas pelo método, sendo 0,05 para o sexo feminino e 0,03 para o sexo masculino. Os valores de $\mathrm{p}$ e os intervalos de confiança não trazem evidências de diferença entre as idades reais e as idades estimadas, visto que os valores de $p$ são superiores a 0,05 $(0,42$ para o sexo feminino e 0,59 para o sexo masculino) e os intervalos de confiança englobam o valor zero.

O valor positivo da diferença, entre as idades reais e as idades estimadas, demonstra que houve uma ligeira subestimação por meio de método de Cameriere. Apesar da subestimação presente neste estudo se apresentar como mínima, há 
relatos na literatura de maiores subestimações, como no estudo de El-Bakary, Hammad e Mohammed (2010), no qual a subestimação se apresentou em -0,26 $\pm 1,21$ para o sexo feminino e $-0,49 \pm 1,03$ para o sexo feminino. Luz et al. (2019) aplicaram o método de Cameriere em uma amostra croata e outra brasileira, observando também a subestimação pelo método. Semelhantemente, Fernandes et al. (2011) relataram que o método de Cameriere subestimou as idades de $54,4 \%$ de sua amostra com indivíduos brasileiros, tendência que se verificou, principalmente, a partir dos 11 anos de idade.

Isto posto, tal distinção de estimativa entre ambos os métodos, fica visível com a análise dos gráficos de Bland-Altman, onde a linha central, a qual representa a diferença entre idade real e idade estimada, se desloca para maiores valores negativos quando utilizado o método de Willems. Contrariamente, a linha central possui uma tendência a se aproximar de zero quando utilizado o método de Cameriere, evidenciando a menor diferença e a melhor distribuição das idades estimadas em torno da idade real dos indivíduos.

Entretanto, no estudo Apaydin e Yasar (2018), as idades estimadas pelo método de Willems apresentaram uma média de subestimação de -0,06 anos. Além disso, por meio dos estudos de Angelakopoulos et al. (2019) e Halilah et al. (2018), foi possível observar uma superestimação do método de Cameriere nas crianças mais jovens pertencentes a uma amostra de 6 a 14 anos da África do Sul e de 5 a 16 anos da Alemanha, respectivamente.

Referente à média entre as idades estimadas por ambos os métodos, é notável que a diferença negativa, presente no método de Willems, influencia os intervalos de confiança negativos da média e também sua diferença com a idade real, entretanto, com uma menor magnitude quando comparado ao método de Willems isoladamente, dado que a mesma apontou um valor de $-0,21$ para o sexo feminino e $-0,18$ para o sexo masculino. Além disso, o valor $p$ se encontra em 0,0014 para o sexo feminino $e$ 0,0035 para o sexo masculino, o que confirma que há evidências de diferenças entre as idades reais e as médias entre as idades estimadas entre os métodos, dado que ambos os valores se encontram abaixo de 0,05.

Neste contexto, é fundamental que as possíveis consequências, de super ou subestimar a idade cronológica de um indivíduo, sejam diferenciadas. No âmbito civil, os falsos positivos ou falsos negativos tendem a não possuir pesos diferentes, ou seja, um não implica em piores consequências que o outro, dado que o direito civil abrange 
inúmeras circunstâncias e cada caso deve ser avaliado separadamente. Entretanto, no âmbito criminal, a superestimação pode trazer implicações indesejáveis, visto que o indivíduo pode ser considerado imputável, e assim, punido legalmente por um resultado falso positivo, uma vez que o mesmo poderia ser alvo apenas de medidas tutelares educativas (BRASIL, 1940; PINCHI et al., 2012).

Em relação à diferença entre os sexos, ambos apresentaram altos coeficientes de correlação, mas é possível observar que o sexo feminino apresentou uma correlação ligeiramente superior quando utilizado o método de Cameriere pelo avaliador 1 e também nas médias entre as idades estimadas por ambos os métodos. Quando utilizado o método de Willems e também, o método de Cameriere pelo avaliador 2, ambos os sexos obtiveram o mesmo Coeficiente de Correlação Intraclasse (ICC) com seu respectivo Intervalo de Confiança 95\%.

Todavia, quando as diferenças, entre as idades reais e as idades estimadas, da amostra feminina são comparadas com a masculina, o método de Cameriere mostra uma maior tendência em subestimar e o método de Willems, uma maior tendência em sobrestimar, na amostra feminina. Essa tendência se evidencia quando são observados os valores das diferenças supracitadas para cada sexo: quando utilizado o método de Cameriere, o valor da diferença para o sexo feminino foi de 0,05 e para o sexo masculino, 0,03; já quando a idade foi estimada pelo método de Willems, a diferença para as meninas foi de $-0,47$ e para os meninos, $-0,39$. Concluindo assim, que os valores masculinos se apresentaram melhor distribuídos em torno da idade real dos indivíduos, diminuindo a diferença desta com a idade estimada.

A maior superestimação para o sexo feminino, quando utilizado o método de Willems et al. (2001), também foi descrita pelo próprio autor durante seu estudo com uma amostra de crianças caucasianas belgas, onde foi apresentado uma média de superestimação para o sexo feminino de 0,2 e de 0,1 para o sexo masculino. Apaydin e Yasar (2018) também encontraram um maior erro para o sexo feminino quando utilizado o método de Willems, sendo uma subestimação de 0,062 para o sexo feminino e 0,056 para o sexo masculino. Entretanto, no estudo de El-Bakary, Hammad e Mohammed (2010), as meninas apresentaram menor erro frente aos meninos, quando utilizado o método de Willems, relatando uma superestimação de 0,14 anos para o sexo feminino e 0,29 para o sexo masculino.

Já em relação ao método de Cameriere, Wolf et al. (2016) também constataram uma maior diferença para o sexo feminino, sendo uma média de 0,08 para meninas e 
de 0,07 para meninos. Porém, Apaydin e Yasar (2018) encontraram um menor erro para o sexo feminino quando utilizado o método de Cameriere, sendo uma subestimação de 0,603 para o sexo masculino e 0,550 para o feminino.

Em relação aos diferentes resultados dos estudos supracitados sobre a maior superestimação para as meninas ou para os meninos, Rai et al. (2010) propõem que há diversas causas genéticas, ambientais e geográficas, como o estado nutricional e socioeconômico de determinada população, que ocasionam tais discrepâncias.

Já a diferença entre os sexos se deve, principalmente, ao avançado desenvolvimento feminino quando comparado ao desenvolvimento masculino, principalmente quando se refere à formação dental, visto que as meninas atingem quase todos os estágios do desenvolvimento dental antes dos meninos (BAGIC et al., 2008; LIVERSIDGE; SPEECHLY, 2001).

De um modo geral, fica evidente que ambos os métodos são aplicáveis na amostra estudada, tanto paro sexo feminino quanto masculino, uma vez que apresentaram grandes correlações com as idades reais dos indivíduos. Paralelamente, é possível constatar também, que a média entre os métodos utilizados não aumenta significativamente a correlação com a idade real. 


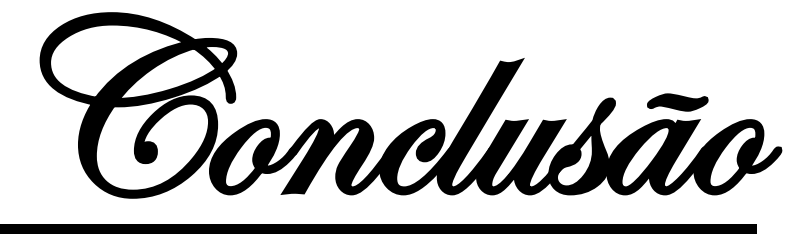




\section{CONCLUSÃo}

Concluiu-se que os métodos de estimativa de idade de Cameriere e Willems possuem grande concordância com as idades reais da amostra utilizada, tanto para o sexo feminino quanto masculino. Já a média obtida entre as idades estimadas pelos dois métodos apresentou um discreto aumento da concordância com a idade real em relação aos métodos separadamente. 
OReferências 


\section{REFERÊNCIAS}

ALQAHTANI, S. et al. Third molar cut-off value in assessing the legal age of 18 in Saudi population. Forensic Sci Int, v. 272, p. 64-7, 2017.

ALQAHTANI, S.J.; HECTOR, M.P.; LIVERSIDGE, H.M. Brief Communication: The London Atlas of Human Tooth Development and Eruption. Am J of Phys Anthropol, v. 142 , p. $481-90,2010$.

ANASTÁCIO, A.C.R. Estimativa médico-legal da idade pela proporção polpa/dente numa população portuguesa: validação do método de Cameriere em pré-molares inferiores. 2016. 51 f. Dissertação de mestrado - Faculdade de Medicina Dentária, Universidade de Lisboa, Lisboa, 2016.

ANDRADE, L. Aplicação dos métodos de identificação humana post mortem no IML Estácio de Lima no período de janeiro de 2011 a dezembro de 2015. Perspec Medicina Legal Per Med, v. 4, 2017.

ANGELAKOPOULOS, $\mathrm{N}$. et al. Age estimation by measuring open ápices in teeth: a new formula for two samples of South African black and white children. Int J Legal Med, p. 1-8, 2019.

APAYDIN, B.K.; YASAR, F. Accuracy of the Demirjian, Willems and Cameriere Methods of Estimating Dental Age on Turkish children. Nigerian Journal of Clinical Practice, v. 21, n. 3, p. 257-63, 2018.

ARAÚJO, L.G. et al. A identificação humana de vítimas de desastres em massa: a importância e o papel da Odontologia Legal. RFO, Passo Fundo, v. 18, n. 2, p. 2249, 2013.

ARAÚJO, M.E.C.; PASQUALI, L. Histórico dos processos de identificação. Brasília: LabPAM, 2006.

ARAÚJO, M.M.A. Cronologia da mineralização dos dentes canino, pré-molares e segundo molar permanentes inferiores, entre maranhenses de seis a quartorze anos de idade. 2000. Tese de Doutorado - Faculdade de Odontologia de São José dos Campos, Universidade Estadual Paulista, São José dos Campos, 2000.

BAGIC, I.C. et al. Dental Age Estimation in Children Using Orthopantomograms. Acta Stomatol Croat, v. 42, n. 1, p. 11-8, 2008.

BRASIL. Código Penal. Decreto-Lei № 2.848, de 7 de dezembro de 1940. Brasília, DF, 1940.

BRASIL. Decreto-Lei № 10.741, de 1 de outubro de 2003. Dispõe do Estatuto do Idoso e dá outras providências. Brasília, DF, 2003. 
BRASIL. Resolução CNS № 466, de 12 de dezembro de 2012. Aprova as diretrizes e normas regulamentadoras de pesquisa envolvendo seres humanos. Brasília, DF, 2012.

BUCHAIM, R.L.; ISSA, J.P.M. Manual de Anatomia Odontológica. In: COSTA, P.B. et al. Odontologia Legal e sua interface com a anatomia humana. Barueri: Manole Ltda, 2018. cap. 15, p. 171-89.

CAMERIERE, R. et al. The comparison between measurement of open apices of third molars and Dermijian stages to test chronological age of over 18 wear olds in living subjects. Int J Legal Med, v. 122, n. 6, p. 493-7, 2008.

CAMERIERE, R.; FERRANTE, L.; CINGOLANI, M. Age estimation in children by measurement of open apices in teeth. Int J Legal Med, v. 120, p. 49-52, 2006.

CARVALHO, A.C.A. et al. Métodos de análise de maturação óssea e estimativa da idade. R Ci méd biol, v. 9, supl. 1, p. 95-103, 2010.

CARVALHO, S.P.M. et al. A utilização de imagens na identificação humana em odontologia legal. Radiol Bras, São Paulo, v. 42, n. 2, p. 125-30, 2009.

CASTRO, J.C.B.B. Antropometria óssea e identificação do sexo. 2017. 69 f. Dissertação de Mestrado - Faculdade de Odontologia de Piracicaba, Universidade Estadual de Campinas, Piracicaba, 2017.

CONSELHO FEDERAL DE ODONTOLOGIA (CFO). Consolidação das normas para procedimentos nos Conselhos de Odontologia. Aprovada pela Resolução no 63 de 2005.

CORREIA, A.M.; BEZERRA, T.P. Estimativa de Idade em Humanos, Parte C Exame Odontológico. In: COUTO, R.C. Perícias em Medicina e Odontologia Legal. Rio de Janeiro: MedBook, 2011. p. 517-26.

COSTA, L.R.S. Estimativa da idade através da análise das suturas craniana: contribuição da antropologia forense. 2002. 233 f. Tese de doutorado - Faculdade de Odontologia de Piracicaba, Universidade de Campinas, Piracicaba, 2002.

DERMIJIAN, A.; GOLDSTEIN, H.; TANNER, J.M. A new system of dental age estimation. Hum Biol, v. 45, n. 2, p. 211-27, 1973.

DOMINGUEZ, J.A.; BAENINGER, R. Programa de reassentamento de refugiados no Brasil. Anais da Associação Brasileira de Estudos Populacionais, 2006.

DUARTE, M.E.Q. et al. Fatores associados a cronologia de erupção de dentes decíduos: revisão de literatura. Revista da Universidade Vale do Rio Verde, v. 9, n. 1, p. 139-51, 2011.

EKIZOGLU, O. et al. Forensic age diagnostics by magnetic resonance imaging of the proximal humeral epiphysis. Int J Legal Med, v. 133, p. 249-56, 2019. 
EL-BAKARI, A.A.; HAMMAD, A.M.; MOHAMMED, F. Dental age estimation in Egyptian children, camparison between two methods. J Forensic Leg Med, v. 17, p. 363-7, 2010.

FEREMBACH, D.; SCHWIDETZKY, I.; STLOUKAL, M. Recommandations pour déterminer l'âge et le sexe sur le squelette. Bull Mem Soc Anthropol Paris, v. 6, p.7-45, 1979.

FERNANDES, M.M. et al. Age Estimation by Measurements of Developing Teeth: Accuracy of Cameriere's Method on a Brazilian Sample. J Forensic Sci, v. 56, p. 1616-9, 2011.

FRANCO, A. et al. Applicability of Willems model for dental age estimations in Brazilian children. Forensic Sci Int, v. 231, n. 1-3, p. 401.e1-401.e4, 2013.

FREIRE, J.J.B. Estatura: dado fundamental em antropologia forense. 2000. $126 \mathrm{f}$. Dissertação de mestrado - Faculdade de Odontologia de Piracicaba, Universidade de Campinas, Piracicaba, 2000.

FREITAS, J.A.S. et al. Variabilidade das fases de formação e erupção dos dentes permanentes. Ortodontia, v.23, n. 2, p. 29-39, 1990.

FREITAS, R.P. Sistemas de identificação humana no âmbito criminal. 2013. 38 f. Trabalho de Conclusão de Curso (Especialização em segurança pública) Universidade Estadual da Paraíba, Campina Grande 2013.

FURTUNATO, V.A.O.; SOUTO, G.B.B.; PIANA, T.D. The age estimate based on tooth mineralization using Nicodemo, Moraes and Médici's Method (1974) in the Southern Bahia Population: Pilot Study. BJFS, Medical Law and Bioethics, v. 8, n. 1, p. 25-35, 2018.

GALIC, I. et al. Accuracy of Cameriere, Haavikko, and Willems radiographic methods on age estimation on Bosnian-Herzegovian children age groups 6-13. Int $\mathbf{J}$ Legal Med, v. 125, p. 315-21, 2011.

GIBELLI, D.; DE ANGELIS, D.; CATTANEO, C. Radiological pitfalls of age estimation in adopted children: a case report. Minerva Pediatr, v. 67, n. 2, p. 203-8, 2015.

GONÇALVES, A.C.S.; ANTUNES, J.L.F. Estimativa da idade em crianças baseada nos estágios de mineralização dos dentes permanentes, com finalidade Odontolegal. Odontologia e Sociedade, v. 1, n. 1/2, p. 55-62, 1999.

GOUVEIA, R.G. Estimativa de idade por métodos dentários: breve revisão. 2016. 42 f. Dissertação de mestrado - Faculdade de Medicina, Universidade de Coimbra, Coimbra, 2016.

GUSTAFSON, G. Age determination on teeth. J Am Dent Assoc, v. 41, n. 1, p. 4554, 1950. 
HALILAH, T. et al. Age estimation in 5-16-year-old children by measurement of open apices: North German formula. Forensic Sci Int, v. 293, p. 103.e1-8, 2018.

INTERNACIONAL CRIMINAL POLICE ORGANIZATION (INTERPOL). Disaster Victim Identification Guide, 2018.

JAVADINEJAD, S.; SEKHAVATI, H.; GHAFARI, R. A comparison of the accuracy of four age estimation methods based on panoramic radiography of developing teeth. JODDD, v. 9, n. 2, p. 72-8, 2015.

KARKHANIS, S.; MACK, P.; FRANKLIN, D. Age estimation standards for a Western Australian population using the dental age estimation technique developed by Kvaal et al. Forensic Sci Int, v. 235, p. 104.e1-6, 2014.

KURITA, L.M. Aplicabilidade de métodos de estimativa de idade óssea e dentária em brasileiros, cearenses. 2004. $134 \mathrm{f}$. Tese de doutorado - Faculdade de Odontologia de Piracicaba, Universidade de Campinas, Piracicaba, 2004.

KVAAL, S.I. et al. Age estimation of adults from dental radiographs. Forensic Sci Int, v. 74, p. 175-85, 1995.

LIVERSIDGE, H.N.; SPEECHLY, T. Growth of permanent mandibular teeth of British children aged 4 to 9 years. Ann Hum Biol, v. 28, n. 3, p. 256-62, 2001.

LUZ, L.C.P. et al. Accuracy of four dental age estimation methodologies in Brazilian and Croatian children. Science \& Justice, v. 59, p. 442-7, 2019.

MAFRA, R.P. et al. Desenvolvimento dental: aspectos morfogenéticos e relações com as anomalias dentárias do desenvolvimento. Rev Bras de Odontol, v. 69, n. 2, p. 232-7, 2012.

MANI, S.A. et al. Comparison of two methods of dental age estimation in 7-15-yaerold Malays. Int J Paediatr Dent, v. 18, p. 380-8, 2008.

MANJUNATHA, B.S.; SONI, N.K. Estimation of age from development and eruption of teeth. J Forensic Dent Sci, v. 6, n. 2, p. 73-6, 2014.

MASSLER, M.; SCHOUR, I. Studies in tooth development: Theories of eruption. Am J Orthodont Oral Surg, v. 27, n. 10, p. 552-76, 1941.

MELANI, R.F.H. Identificação humana em vítimas de carbonização: análise odonto-legal através da microscopia eletrônica. 1998. 96 f. Tese de doutorado Faculdade de Odontologia de Piracicaba, Universidade de Campinas, Piracicaba, 1998.

MODESTO, T.O.P.; JUNIOR, E.F. Identificação humana através da Rugoscopia Palatina. Revista Interdisciplinar de Direito, v. 11, n. 2, p. 461-72, 2017. 
MOREIRA, D.C. Sistema semiautomático de identidade vocal forense. 2013. Dissertação de mestrado - Universidade Federal de Campina Grande, Campina Grande, 2013.

MORENO, M.B.P.; PONTES, T.J.P.; RABELLO, P.M. Utilização da Tabela de cronologia de mineralização dental de Nicodemo, Morais e Médici Filho na estimativa da idade de paraibanos. Saúde, Ética \& Justiça, v. 19, n. 1, p. 35-44, 2014.

MOYERS, E.R. Ortodontia. Rio de Janeiro: Guanabara Koogan, 1991.

NETO, F.H.; ALMEIDA, S.M.; LEITE, C.C. Estudo comparativo dos métodos de estimativa de idade óssea de Greulich \& Pyle e Tanner \& Whitehouse. Pesqui Odontol Bras, v. 14, n. 4, p. 378-84, 2000.

NOLLA, C.M. The development of permanente teeth. J Dent Child, v. 27, p. 254-66, 1960.

OLIVEIRA, F.T. Estimativa de idade cronológica por meio de avaliação radiográfica da mineralização de terceiros molares e altura do ramo da mandíbula. 2010. 96 f. Tese de Doutorado - Faculdade de Odontologia de Bauru, Universidade de São Paulo, Bauru, 2010.

OTTO, I.A. Estimativa da ancestralidade de crânios não identificados do espaço museológico de odontologia legal e antropologia forense do Rio Grande do Norte. 2016. 21 f. Trabalho de Conclusão de Curso (Graduação) Universidade Federal do Rio Grande do Norte, Natal, 2016.

PATRIANOVA, M.E.; KROLL, C.D.; BÉRZIN, F. Seqüência e cronologia de erupção dos dentes decíduos em crianças do município de Itajaí (SC). Rev Sul-Bras Odontol, v. 7, n. 4, p. 406-13, 2004.

PINCHI, V. et al. Comparision of the applicability of four odontological methods for age estimation of the 14 years legal threshold in a sample of Italian adolescents. JFOS, v. 30, n. 2, p. 17-25, 2012.

RAI, B.; ANAND, S.C. Tooth Developments: An Accuracy of Age Estimation of Radiographic Methods. World J Med Sci, v.1, n. 2, p. 130-2, 2006.

RAI, B. et al. Age estimation in children by measurement of open apices in teeth: $\mathrm{Na}$ Indian formula. Int J Legal Med, v. 124, n. 3, p. 237-41, 2010.

RITZ-TIMME, S. et al. Age estimation: the state of the art in relation to the specific demands of forensic practise. Int J Legal Med, v. 113, n. 3, p. 129-36, 2000.

SALIBA, C.A. et al. Estimativa da idade pela mineralização dos dentes, através de radiografias panorâmicas. ROBRAC, v. 6, n. 22, p. 14-6, 1997.

SANTINHO, M.C. Reconstruindo memórias: jovens refugiados em Portugal. Saúde Soc, v. 18, n. 4, p. 582-9, 2009. 
SANTANA, C. Cultural humility: a strategic concept for addressing refugee health in Brazil. Cad Saúde Pública, v. 34, n. 11, 2018.

SANTORO, V. et al. Forensic age estimation of living individuals: A retrospective analysis. Forensic Sci Int, v. 193, p. 129.e1-4, 2009.

SATO, A.M. et al. Radiografias panorâmicas: abrangência multidisciplinar. 2005. 48 f. Monografia (Especialização em Radiologia) - Faculdade de Odontologia de Piracicaba, Universidade de Campinas, Piracicaba, 2005.

SAUNDERS, B.Y.E. The teeth a test of age, considered with reference to the factory children. Adressed to the members of both Houses of Parliament. London: H. Renshaw, 1837.

SCHMELING, A. et al. Age estimation. Forensic Sci Int, v. 165, p. 178-81, 2007.

SCHMIDT, C.M. Estimativa da idade e sua importância forense. 2004. $134 \mathrm{f}$. Dissertação de mestrado - Faculdade de Odontologia de Piracicaba, Universidade de Campinas, Piracicaba, 2004.

SHAH, P. et al. Teeth in forensics: A review. Indian J Dent Res, v. 30, n. 2, p. 291-9, 2019.

SHEDGE, R.; KANCHAN, T. Cranial sutures and age estimation - a few reflections. J Forensic Leg Med, v. 61, p. 144, 2019.

SOARES, A.T.C. Perfil antropológico das ossadas analisadas no Centro de Medicina Legal (CEMEL) da Faculdade de Medicina de Ribeirão Preto - USP. 2008. 171 f. Dissertação de mestrado - Faculdade de Medicina de Ribeirão Preto, Universidade de São Paulo, Ribeirão Preto, 2008.

SUAREZ-KURTZ, G. Farmacogenômica e a diversidade genética da população brasileira. Caderno de Saúde Pública, v. 25, n. 8, p. 1650-1, 2009.

SULZLER, K.E. et al. Cronologia de erupção do primeiro molar permanente em crianças dos municípios de Santa Helena e Três Barras do Paraná, PR/Brasil. R bras ci Saúde, v. 22, n. 3, p. 189-194, 2018.

SWAMI, D. et al. Age estimation from eruption of temporary teeth in himachal pradesh. J Forensic Med Toxicol, v. 9, p. 3-7, 1992.

TORNAVOI, D.C.; SILVA, R.H.A. Rugoscopia palatina e a aplicabilidade na identificação humana em odontologia legal: revisão de literatura. Saúde, Ética \& Justiça, v. 15, n. 1, p. 28-34, 2010.

VELHO, J.A.; GEISER, G.C.; ESPINDULA, A. Ciências Forenses: uma introdução às principais áreas da criminalística moderna. In: GUIMARÃES, M.A.; FRANCISCO, R.A.; EVISON, M.P. Antropologia Forense. Campinas: Millennium Editora, 2017. cap 4, p. 57-82. 
WILLEMS, G. et al. Dental age estimation in Belgian children: Dermijian's technique revisited. J Forensic Sci, v. 46, n. 4, p. 893-5, 2001.

WOLF, T.G. et al. Dental age assessment in 6- to 14-year old German children: comparison of Cameriere and Demirjian methods. BMC Oral Health, v. 16, n. 1, p. 120, 2016.

ZILIO, F.; BASUALDO, A.; CRUZ, R.A. Meios de identificação odontolegal. VI Mostra de Pesquisa e Pós-Graduação IMED, 2012. 
ANEXO A - Parecer Consubstanciado do CEP.

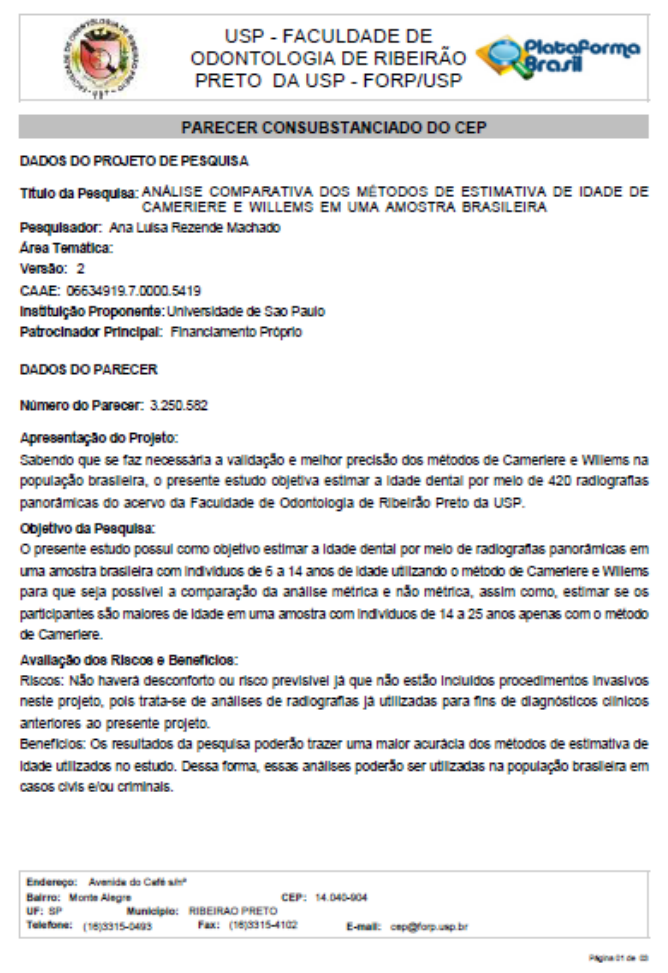
USP - FACULDADEDE USP - FACULDADE DE PRETO DA USP - FORP/USP

Cronograma.par

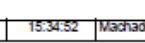
1 Acerto

Sittuaçso do Parecer:

Aprovasdo
Necsasta Apreclaça da CONEP.

RIBEERAO PRETT 08 de ADrI de 2019

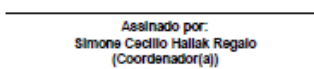

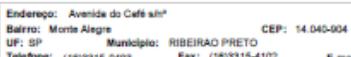

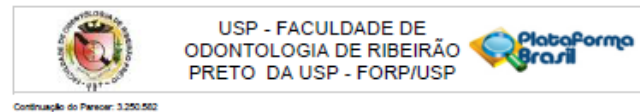

Comentarios $\theta$ Consideraçoes sobre a Pesqulas:

Projeto bem dellneado, embasado dentincamente e nas normatvas do CEP FORP, ISP e CONEP.

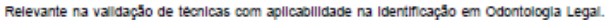
Conalderassoes sobre os Termos de apresentaça obrigatoria:

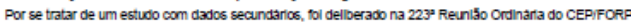
de 14:02:2019 que o pesquisador deveria acequar a Fona de Rosto cnoe o numero de particpantes da pesquisa era igual a 420. O pesquisador apresentiou uma Folha de Rosto com o numero de partclpantes Igual a ZERO e consequentementie um novo arquivo Informaģes Basicass do Projeto na Platatorma Brasi com a adequarşo dos campos que intormam o numero de partldipartes da pesqusa.

Racomendacsees:
NS5o ha

Conclusoes ou Pendernclas e Lata de Inadequaços:

Projetto aprovasto.

Considderaspoes Finals a criterio do CEP.

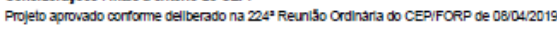

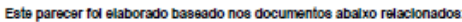

\begin{tabular}{|c|c|c|c|c|}
\hline Tho Documentio & Avquino & Postagem & Rutor & 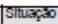 \\
\hline 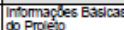 & PS INFORMACOES GKSICAS_DO_P & $\begin{array}{l}19022019 \\
170425\end{array}$ & & Aceto to \\
\hline \begin{tabular}{|l|} 
Fonaticie rosto \\
\end{tabular} & 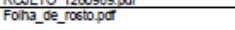 & 190225019 & Ana Luisa Rezende & ADet to \\
\hline ouros & 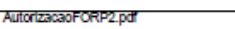 & $\frac{170.0347}{2301 / 2019}$ & 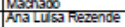 & A0210 \\
\hline Outros & 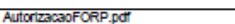 & $\frac{15.24 .26}{23012019}$ & $\begin{array}{l}\text { Macasaco } \\
\text { Ana Luisa Rezende }\end{array}$ & Acesto to \\
\hline $\begin{array}{l}\text { Dedarazo de } \\
\text { insthich oe }\end{array}$ & Ifiriaestrutura.par & $\begin{array}{c}\frac{15 \cdot 23: 34}{2301012019} \\
12.25: 44\end{array}$ & 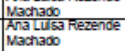 & \\
\hline 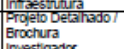 & Projero.pd & $\begin{array}{l}23012019 \\
12: 16: 29\end{array}$ & $\begin{array}{l}\text { Ana Lukas Rezende } \\
\text { Machasoo }\end{array}$ & \\
\hline Orgamention & Orcamento.pdt & 222012019 & $\begin{array}{l}\text { Ana Luisa Rezende } \\
\text { Machaso }\end{array}$ & $\overline{A D e t}$ \\
\hline cronos & Cronograma.pat & & Anal Lusa Rezende & ex \\
\hline
\end{tabular}

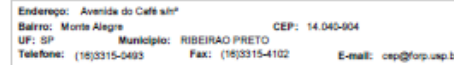


APÊNDICE A - Idades reais e idades estimadas para o sexo feminino (amostra 1) por ambos os métodos e avaliadores.

\begin{tabular}{|c|c|c|c|c|}
\hline \multirow[b]{2}{*}{ Idade real } & \multicolumn{2}{|c|}{ AVALIADOR 1} & \multicolumn{2}{|c|}{ AVALIADOR 2} \\
\hline & $\begin{array}{l}\text { Idade estimada } \\
\text { (Cameriere) }\end{array}$ & $\begin{array}{l}\text { Idade estimada } \\
\quad \text { (Willems) }\end{array}$ & $\begin{array}{l}\text { Idade estimada } \\
\text { (Cameriere) }\end{array}$ & $\begin{array}{l}\text { Idade estimada } \\
\text { (Willems) }\end{array}$ \\
\hline 8,6 & 9,1 & 9,1 & 8,3 & $\begin{array}{c}8,7 \\
101\end{array}$ \\
\hline 9,2 & 10,0 & 9,4 & 9,0 & 10,1 \\
\hline 14,7 & 13,7 & 15,8 & 13,0 & 15,8 \\
\hline 10,9 & 11,2 & 10,7 & 9,5 & 10,1 \\
\hline 10,9 & 11,0 & 11,0 & 11,1 & 12,3 \\
\hline 10,5 & 11,0 & 11,0 & 10,3 & 11,3 \\
\hline 14,2 & 13,7 & 15,8 & 13,7 & 15,8 \\
\hline 13,0 & 12,4 & 12,9 & 11,7 & 12,9 \\
\hline 14,0 & 13,7 & 13,8 & 13,0 & 15,8 \\
\hline 9,0 & 10,2 & 10,1 & 10,2 & 10,0 \\
\hline 12,6 & 13,7 & 13,8 & 13,0 & 13,8 \\
\hline 13,2 & 10,9 & 12,0 & 11,0 & 12,0 \\
\hline 8,0 & 8,0 & 9,1 & 7,9 & 8,4 \\
\hline 14,4 & 13,7 & 15,8 & 13,7 & 15,8 \\
\hline 14,5 & 13,7 & 15,8 & 13,7 & 15,8 \\
\hline 13,5 & 12,5 & 13,8 & 12,6 & 12,7 \\
\hline 8,0 & 7,5 & 8,2 & 7,7 & 8,1 \\
\hline 14,9 & 13,7 & 15,8 & 13,0 & 14,8 \\
\hline 8,6 & 8,7 & 9,4 & 8,9 & 9,4 \\
\hline 10,6 & 11,7 & 11,5 & 11,0 & 11,5 \\
\hline 13,5 & 13,0 & 13,8 & 13,0 & 13,8 \\
\hline 11,0 & 11,2 & 11,5 & 11,0 & 11,0 \\
\hline 14,1 & 13,7 & 15,8 & 13,0 & 13,8 \\
\hline 12,4 & 12,4 & 12,9 & 11,7 & 13,3 \\
\hline 12,5 & 12,4 & 13,8 & 12,4 & 13,8 \\
\hline 7,1 & 7,4 & 8,2 & 7,4 & 8,1 \\
\hline 12,7 & 11,0 & 12,2 & 10,3 & 12,7 \\
\hline 9,9 & 11,1 & 10,7 & 11,1 & 10,7 \\
\hline 6,0 & 6,7 & 7,9 & 7,0 & 7,9 \\
\hline 6,7 & 6,3 & 7,0 & 6,8 & 6,5 \\
\hline 11,0 & 11,2 & 10,1 & 10,3 & 10,1 \\
\hline 8,4 & 7,7 & 8,0 & 7,6 & 8,4 \\
\hline 10,6 & 11,0 & 10,1 & 10,0 & 10,1 \\
\hline 11,4 & 11,2 & 10,7 & 11,1 & 11,0 \\
\hline 9,4 & 8,4 & 9,1 & 8,4 & 9,4 \\
\hline 8,8 & 7,8 & 8,0 & 8,2 & 8,6 \\
\hline 12,0 & 11,0 & 12,0 & 10,9 & 12,9 \\
\hline 13,3 & 13,7 & 13,8 & 12,4 & 13,8 \\
\hline 12,9 & 12,4 & 12,9 & 11,0 & 13,8 \\
\hline 9,6 & 11,0 & 10,0 & 10,5 & 9,4 \\
\hline 14,1 & 13,7 & 15,8 & 13,7 & 13,8 \\
\hline 8,6 & 9,3 & 9,6 & 8,7 & 9,5 \\
\hline 8,7 & 11,0 & 10,7 & 10,3 & 9,4 \\
\hline 13,1 & 13,0 & 13,8 & 12,3 & 13,8 \\
\hline 10,2 & 10,9 & 10,7 & 10,2 & 10,1 \\
\hline 13,4 & 13,0 & 13,8 & 13,0 & 13,8 \\
\hline 14,9 & 13,0 & 13,8 & 12,4 & 12,6 \\
\hline 12,3 & 13,0 & 13,8 & 12,4 & 15,8 \\
\hline 11,4 & 13,0 & 12,9 & 12,3 & 12,9 \\
\hline 8,0 & 7,7 & 8,0 & 7,9 & 8,0 \\
\hline 7,2 & 7,8 & 7,9 & 8,6 & 8,0 \\
\hline 12,9 & 12,7 & 12,9 & 12,7 & 12,7 \\
\hline 12,2 & 13,0 & 13,8 & 12,4 & 13,8 \\
\hline 9,9 & 9,3 & 10,1 & 8,5 & 10,1 \\
\hline
\end{tabular}


APÊNDICE B - Idades reais e idades estimadas para o sexo masculino (amostra 2) por ambos os métodos e avaliadores.

\begin{tabular}{|c|c|c|c|c|}
\hline \multicolumn{3}{|c|}{ AVALIADOR 1} & \multicolumn{2}{|c|}{$\begin{array}{l}\text { AVALIADOR } 2 \\
\end{array}$} \\
\hline Idade real & $\begin{array}{l}\text { Idade estimada } \\
\text { (Cameriere) }\end{array}$ & $\begin{array}{l}\text { Idade estimada } \\
\text { (Willems) }\end{array}$ & $\begin{array}{l}\text { Idade estimada } \\
\text { (Cameriere) }\end{array}$ & $\begin{array}{l}\text { Idade estimada } \\
\text { (Willems) }\end{array}$ \\
\hline 10,8 & 11,4 & 11,3 & 11,3 & 12,0 \\
\hline 14,7 & 14,1 & 16,0 & 13,4 & 14,3 \\
\hline 8,3 & 9,7 & 10,3 & 9,8 & 9,9 \\
\hline 13,1 & 12,0 & 12,4 & 12,1 & 14,3 \\
\hline 11,3 & 11,3 & 10,9 & 10,5 & 10,2 \\
\hline 10,9 & 11,4 & 10,9 & 10,6 & 11,4 \\
\hline 9,5 & 10,6 & 10,3 & 8,9 & 10,5 \\
\hline 9,5 & 10,5 & 10,3 & 9,7 & 11,0 \\
\hline 12,1 & 11,3 & 11,9 & 11,3 & 12,4 \\
\hline 10,7 & 11,3 & 10,7 & 10,5 & 11,6 \\
\hline 8,7 & 8,7 & 9,7 & 8,9 & 8,9 \\
\hline 10,9 & 11,4 & 12,0 & 10,5 & 11,5 \\
\hline 11,8 & 11,2 & 12,0 & 10,6 & 11,4 \\
\hline 8,4 & 8,9 & 8,5 & 7,6 & 8,3 \\
\hline 14,0 & 12,7 & 13,6 & 12,3 & 14,3 \\
\hline 12,8 & 11,2 & 11,9 & 11,3 & 11,2 \\
\hline 11,1 & 11,4 & 10,9 & 11,2 & 10,6 \\
\hline 7,6 & 7,6 & 8,2 & 7,9 & 8,2 \\
\hline 10,4 & 11,4 & 10,9 & 9,8 & 9,6 \\
\hline 14,8 & 13,4 & 13,6 & 13,4 & 14,3 \\
\hline 12,6 & 11,4 & 12,4 & 11,4 & 12,0 \\
\hline 14,4 & 13,4 & 14,3 & 13,4 & 14,3 \\
\hline 9,6 & 9,3 & 9,6 & 8,6 & 8,8 \\
\hline 6,3 & 7,2 & 7,1 & 6,8 & 7,5 \\
\hline 11,3 & 11,3 & 11,6 & 10,6 & 11,6 \\
\hline 13,6 & 12,8 & 13,6 & 12,8 & 12,4 \\
\hline 14,8 & 14,1 & 16,0 & 14,1 & 16,0 \\
\hline 6,8 & 6,8 & 7,1 & 6,9 & 7,5 \\
\hline 12,1 & 12,7 & 11,9 & 12,0 & 12,8 \\
\hline 12,5 & 11,3 & 12,0 & 11,3 & 12,0 \\
\hline 13,0 & 13,4 & 14,3 & 13,4 & 14,3 \\
\hline 13,2 & 13,4 & 14,3 & 13,4 & 14,3 \\
\hline 9,8 & 11,3 & 10,9 & 11,3 & 10,6 \\
\hline 13,2 & 12,1 & 13,2 & 12,1 & 14,3 \\
\hline 10,3 & 11,2 & 10,9 & 11,3 & 10,9 \\
\hline 11,3 & 11,3 & 10,2 & 11,3 & 11,3 \\
\hline 9,8 & 10,5 & 10,9 & 10,4 & 10,9 \\
\hline 13,0 & 11,3 & 12,4 & 11,4 & 12,4 \\
\hline 14,8 & 14,1 & 16,0 & 14,1 & 14,3 \\
\hline 14,8 & 13,4 & 14,3 & 13,4 & 14,3 \\
\hline 12,0 & 11,3 & 12,4 & 12,8 & 12,4 \\
\hline 9,3 & 9,8 & 10,1 & 8,9 & 10,8 \\
\hline 9,6 & 10,0 & 10,1 & 10,0 & 10,1 \\
\hline 10,2 & 11,3 & 10,9 & 11,3 & 11,6 \\
\hline 8,7 & 10,2 & 9,6 & 9,4 & 9,6 \\
\hline 14,0 & 13,4 & 14,3 & 13,4 & 14,3 \\
\hline 9,6 & 9,6 & 9,6 & 9,6 & 9,6 \\
\hline 10,9 & 11,5 & 11,6 & 11,4 & 10,9 \\
\hline 9,2 & 8,0 & 8,3 & 8,0 & 8,9 \\
\hline 8,2 & 9,3 & 9,7 & 9,5 & 9,7 \\
\hline 10,5 & 11,4 & 10,2 & 11,4 & 10,3 \\
\hline 11,6 & 11,3 & 12,0 & 11,3 & 11,9 \\
\hline 8,7 & 8,4 & 8,9 & 8,6 & 9,1 \\
\hline 12,8 & 12,8 & 13,6 & 12,8 & 13,6 \\
\hline
\end{tabular}

